\title{
Afferent Input to Nucleus Submedius in Rats: Retrograde Labeling of Neurons in the Spinal Cord and Caudal Medulla
}

\author{
Robert J. Dado and Glenn J. Giesler, Jr. \\ Department of Cell Biology and Neuroanatomy, Graduate Program in Neuroscience, University of Minnesota, Minneapolis, \\ Minnesota 55455
}

In cats, spinal and medullary input to the thalamic nucleus submedius ( $\mathrm{Sm}$ ) arises almost exclusively from neurons in the marginal zone. As a result, it has been proposed that Sm may be specifically involved in nociception. In the present study, we determined the locations of neurons in the spinal cord and caudal medulla that project to $\mathrm{Sm}$ in rats. lontophoretic injections of Fluoro-Gold or pressure injections of Fast blue were made into Sm. In each of the 6 rats that received small injections of Fluoro-Gold into $\mathbf{S m}$, only a small number (mean $=90$ ) of retrogradely labeled neurons were found throughout the 18 segments of the spinal cord examined. Surprisingly, almost no labeled neurons ( $<1 \%$ ) were counted in the marginal zone of the spinal cord. The majority were located in the deep dorsal horn and intermediate zone/ ventral horn. In contrast, many neurons were labeled in the marginal zone of nucleus caudalis. Injections of Fluoro-Gold into any of a number of nuclei near Sm also labeled only a small number of neurons in the spinal cord and almost no neurons In the marginal zone. Using identical injection parameters, we injected Fluoro-Gold into the ventrobasal complex or posterior thalamic group. Hundreds of neurons in the spinal cord, including many in the marginal zone, were labeled following these injections. These results indicate that the techniques used to inject Fluoro-Gold into Sm were capable of labeling many projection neurons, including those in the marginal zone. Larger pressure injections of Fast blue were also made into $\mathrm{Sm}$ of 3 rats. The distribution of labeled neurons in nucleus caudalis and the spinal cord was similar to that following iontophoretic injections of Fluoro-Gold. Again, few marginal zone neurons were labeled in the spinal cord in any of these rats. Therefore, our results indicate that few spinothalamic tract neurons appear to project to Sm or any of several adjacent nuclei, and virtually no marginal zone neurons in the spinal cord project to these areas.

Several anterograde tracing studies in rats, cats, and monkeys have shown that neurons in the spinal cord (Craig and Burton, 1981; Mantyh, 1983a, b; Peschanski et al., 1983; Robertson et al., 1983; Craig and Burton, 1985) and spinal trigeminal nucleus

\footnotetext{
Received Feb. 5, 1990; revised Apr. 5, 1990; accepted Apr. 9, 1990.

Supported by NS25932. We thank Drs. C. Honda, J. Katter, and R. Burstein for critically reading the manuscript. We also thank Ms. C. Andersen and Mr. H. Truong for technical assistance and Mr. G. Sedgewick and Mr. T. Truong for photographic work.

Correspondence should be addressed to G. J. Giesler, Jr., Department of Cell Biology and Neuroanatomy, University of Minnesota, 4-135 Jackson Hall, 321 Church St. S.E., Minneapolis, MN 55455.

Copyright (C) 1990 Society for Neuroscience $0270-6474 / 90 / 082672-15 \$ 03.00 / 0$
}

(Craig and Burton, 1981; Peschanski, 1984; Fig. 33 by L. Kruger, J. L. Krettek, R. F. Young, and J. Curtis in Albe-Fessard et al., 1985; Ma et al., 1988) project to the dorsal portion of the thalamic nucleus submedius (Sm). The input is topographically organized; the projection from the spinal cord is to the rostral half of $\mathrm{Sm}$, and the projection from the spinal trigeminal nuclei terminates in the caudal half of the nucleus (Craig and Burton, 1981). Retrograde tracing studies using HRP suggest that in cats, the input to $\mathrm{Sm}$ arises almost exclusively from neurons in the marginal zone of the spinal and medullary dorsal horns (Craig and Burton, 1981). Based on these anatomical data and the fact that many neurons in the marginal zone respond specifically to noxious stimuli (Christensen and Perl, 1970; Kumazawa et al., 1975; Price et al., 1976), Craig and Burton (1981) proposed that Sm may have an important role in nociception.

Recent electrophysiological and anatomical studies in rats support this hypothesis. Neurons have been recorded in Sm that respond specifically to noxious mechanical and thermal stimuli (Dostrovsky and Guilbaud, 1988; Miletic and Coffield, 1989). Others respond to innocuous mechanical stimuli, but respond at higher frequencies to noxious stimulation (Miletic and Coffield, 1989). Many nociceptive neurons in Sm have large bilateral receptive fields (Dostrovsky and Guilbaud, 1988; Miletic and Coffield, 1989), suggesting that $\mathrm{Sm}$ is not likely to play a role in sensory-discriminative aspects of nociception. Also, noxious mechanical stimulation of the hindlimb induces expression of c-fos-like protein in a number of neurons within Sm in rats (Bullitt, 1989). Expression of c-fos is thought to be an anatomical marker for increased activity in neurons (Hunt et al., 1987). Anatomical studies in rats (Jones and Leavitt, 1974; Krettek and Price, 1977; Herkenham, 1979; Ma et al., 1988) and cats (Craig et al., 1982) have demonstrated that neurons in Sm project to the ventrolateral orbital cortex, suggesting that Sm may convey nociceptive information to the cortex (Craig et al., 1982).

The locations of neurons projecting to $\mathrm{Sm}$ in species other than the cat have not been investigated thoroughly. Since many behavioral, pharmacological, and physiological studies of pain have been done in rats, we thought it would be valuable to determine the inputs to $\mathrm{Sm}$ in this species. In the present study, the sources of afferent input to Sm from the spinal cord and caudal medulla were examined following small injections of sensitive fluorescent retrograde tracers into Sm of rats.

\section{Materials and Methods}

Male Sprague-Dawley rats (320-570 gm) were anesthetized with sodium pentobarbital and placed in a stereotaxic frame. In each of 17 rats, attempts were made to inject Fluoro-Gold (FG; $1 \%$ solution dissolved in $0.1 \mathrm{M} \mathrm{NaCl}$ ) iontophoretically into $\mathrm{Sm}$. Iontophoretic injections were 
chosen because of the ability to restrict the size and spread of the in jections (Schmued and Fallon, 1986; Pieribone and Aston-Jones, 1988). Glass micropipettes with tip diameters of approximately $10 \mu \mathrm{m}$ were used. In each case, Fluoro-Gold was iontophoretically injected using approximately $48 \mu \mathrm{A}$-min of anodal current. Injections were made in approximately the anterior-posterior center of Sm to enable spread of the injection into both the spinal and trigeminal zones of input. In each of 2 additional rats, an injection was made at 2 different anteriorposterior coordinates to insure that the entire rostrocaudal extent of Sm was filled with the tracer.

Following a 3-5 d survival period (Burstein et al., 1990a, b), rats were deeply anesthetized with sodium pentobarbital and perfused with $0.9 \%$ saline followed by $10 \%$ formalin. The brain, including caudal medulla, and 18 spinal cord segments (C1-2, C4-5, C7-8, T4, T6, T8, T12, L13 , L4-5, L6-S2) were identified and removed. The diencephalon from each rat was cut transversely on a freezing microtome at $100 \mu \mathrm{m}$ immediately following dissection. Identified spinal cord segments and caudal medulla were placed in $10 \%$ formalin for at least $12 \mathrm{hr}$ and subsequently sectioned at a thickness of $40 \mu \mathrm{m}$. Alternate serial sections were mounted and sealed under a coverslip with DPX. Sections were examined microscopically using reflected ultraviolet illumination. Injection sites were initially reconstructed using dark-field microscopy. To confirm the location and boundaries of nucleus submedius, the tissue was subsequently counterstained with cresyl violet or Neutral red and reexamined using bright-field microscopy. Injection sites and retrogradely labeled neurons in the caudal medulla and the spinal cord were reconstructed with the aid of a camera lucida drawing attachment.

Iontophoretic injections of Fast blue were attempted but were not successful. The tips of the micropipettes cvidently became plugged, and subsequently, it was difficult to maintain the current necessary to inject adequate amounts of the tracer. Therefore, in each of 3 rats, a pressure injection (100-200 $\mathrm{nl}$ ) of a $1 \%$ solution of Fast blue dissolved in $0.1 \mathrm{M}$ $\mathrm{NaCl}$ was made into $\mathrm{Sm}$. Injections were made using a micropipette attached to the end of a Hamilton microsyringe. One rat was allowed to survive $4 \mathrm{~d}$; the other 2 were allowed $11 \mathrm{~d}$ because it has been suggested that longer survival periods are required for transport of Fast blue to the lumbosacral cord (Craig et al., 1989b). The same areas of brain and spinal cord were processed.

Labeled neurons in the spinal cord were classified according to their location in 1 of 5 easily recognized areas: superficial dorsal horn, deep dorsal horn, intermediate zone/ventral horn, area around the central canal, lateral spinal nucleus/lateral cervical nucleus (Burstein et al., 1990a). Within the caudal medulla, labcled neurons in the trigeminal nucleus caudalis were classified as either superficial or deep. Neurons were classified as superficial if they were located in the marginal zone, substantia gelatinosa, or the overlying spinal trigeminal tract. Neurons were classified as deep if they were located in an area extending approximately $800 \mu \mathrm{m}$ ventromedially from the ventral border of the substantia gelatinosa. Nucleus caudalis was considered to extend from the pyramidal decussation to the level of the obex (Torvik, 1956).

To evaluate the effectiveness of our techniques, the ventrobasal complex (VBC) and/or posterior thalamic group (Po) was injected in six additional rats. In each of these animals, iontophoretic injections of FG were made using injection currents similar to those used to inject Sm. Survival times were also the same. Injections were made into VBC in 3 rats (VBC1-3) at approximately the same anterior-posterior level as those into nucleus submedius. A second group of 3 rats received singlc injections near the border between Po and VBC (Po/VBC1-3).

\section{Results}

Injection sites of $F G$ were generally spherical and consisted of a dense core of the tracer in which considerable necrosis was evident. This core was surrounded by a diffuse halo of the tracer. No spread of FG dorsally along the micropipette track could be seen following any of the iontophoretic injections (Figs. $1 A ; 2 A$; 3, $A-E ; 4, A-D ; 5 A ; 6 A)$.

\section{Injections of $\mathrm{FG}$ into $\mathrm{Sm}$}

In each of 6 rats (Sm 1-6), the necrotic core of the injection filled much of the dorsal half of Sm (the area that receives input from the spinal cord and spinal trigeminal nuclei). A photomicro- graph of an injection ( $\mathrm{Sm} 1)$ into $\mathrm{Sm}$ is illustrated in Figure $1 A$, $B$. The core of this injection was restricted to $\mathrm{Sm}$. The halo of FG extended into parts of the rhomboid nucleus, nucleus reuniens, and the anteromedial nucleus. The mediolateral diameter of the core of the injection was approximately $525 \mu \mathrm{m}$. The diameter of the injection, including the halo, was approximately $1.2 \mathrm{~mm}$. The entire anterior-posterior extent of Sm was included in the injection (in rats, Sm extends approximately $1.0-1.5 \mathrm{~mm}$ rostrocaudally; Craig and Burton, 1981; Paxinos and Watson, 1986). The injection extended slightly beyond $(100-200 \mu \mathrm{m})$ the anterior limit of $\mathrm{Sm}$. The distribution of neurons that were labeled by this injection in the caudal medulla and spinal cord is illustrated in Figure 2.

Seventy-nine labeled neurons were found bilaterally in the caudal medulla (Fig. 2B). Most were located in the marginal zone of rostral nucleus caudalis. A few were seen in deeper areas of nucleus caudalis. Labeled neurons were also scattered sparsely throughout the reticular formation and the dorsal column nuclei.

A total of 72 retrogradely labeled neurons was found bilaterally throughout the 18 examined spinal cord segments (Fig. $2 C$ ). The majority were found in the deep dorsal horn and intermediate zone/ventral horn. A few were seen in the gray matter around the central canal, the lateral spinal nucleus, and the lateral cervical nucleus. None were seen in the marginal zone at any level of the spinal cord in this rat.

Reconstructions of the injection sites from cases Sm2-6 are shown in Figure 3, $A-E$, respectively. In each of these animals, the necrotic core of the injection included much of the dorsal half of Sm. The mediolateral diameters of the cores of the injections ranged from approximately $500 \mu \mathrm{m}$ in $\mathrm{Sm} 3$ (Fig. 3B) to $750 \mu \mathrm{m}$ in $\mathrm{Sm} 2$ (Fig. $3 A$ ). The diameters of the injections including the halo varied from approximately $975 \mu \mathrm{m}$ in $\mathrm{Sm} 3$ (Fig. $3 B$ ) to $1.4 \mathrm{~mm}$ in $\mathrm{Sm} 2$ (Fig. 3.4). In each case, the halo of the injection extended to the anterior limit of $\mathrm{Sm}$ and in several rats, the halo spread $100-400 \mu \mathrm{m}$ anterior to $\mathrm{Sm}$. The halo of FG extended to the posterior limit of $\mathrm{Sm}$ in 4 of the 6 rats. In the other 2 rats, the halo of FG extended to within approximately 100-200 $\mu \mathrm{m}$ of the caudal limit of Sm.

Following each injection into nucleus submedius ( $\mathrm{Sm} \mathrm{1-6),}$ labeled neurons were seen bilaterally in the caudal medulla. A mean number of approximately 80 neurons was counted in nucleus caudalis in each of the 6 rats. Approximately $81 \%$ of these were located in superficial nucleus caudalis (Fig. 1, E, F) and $19 \%$ in deep nucleus caudalis. Within the superficial nucleus caudalis, a distinctive rostrocaudal distribution of labeled neurons was evident in each rat. The highest concentrations occurred rostrally near the border with nucleus interpolaris (Fig. $2 B)$. These neurons were usually found in clusters in the ventrolateral area of nucleus caudalis (Fig. $1 F$ ). About $15 \%$ of the labeled neurons counted in the caudal medulla were ipsilateral to the injection site in the 3 cases $(\mathrm{Sm} 1-3)$ in which the tracer did not cross the midline. Many labeled neurons were seen in nucleus interpolaris (Fig. $1 G$ ). In each case, a few were also found in the medullary reticular formation and the dorsal column nuclei.

The total number of labeled neurons counted in the 18 examined spinal cord segments in cases $\operatorname{Sm} 2,3$, 4, and 5 was 108, 1,96 , and 35 , respectively. In case $\mathrm{Sm} 6$, an injection was made at 2 different anterior-posterior coordinates (Fig. $3 E$ ). The necrotic core of the anterior injection was well restricted to $\mathrm{Sm}$. However, the posterior injection was centered dorsal to $\mathrm{Sm}$ in the central medial nucleus. The largest number of labeled neu- 

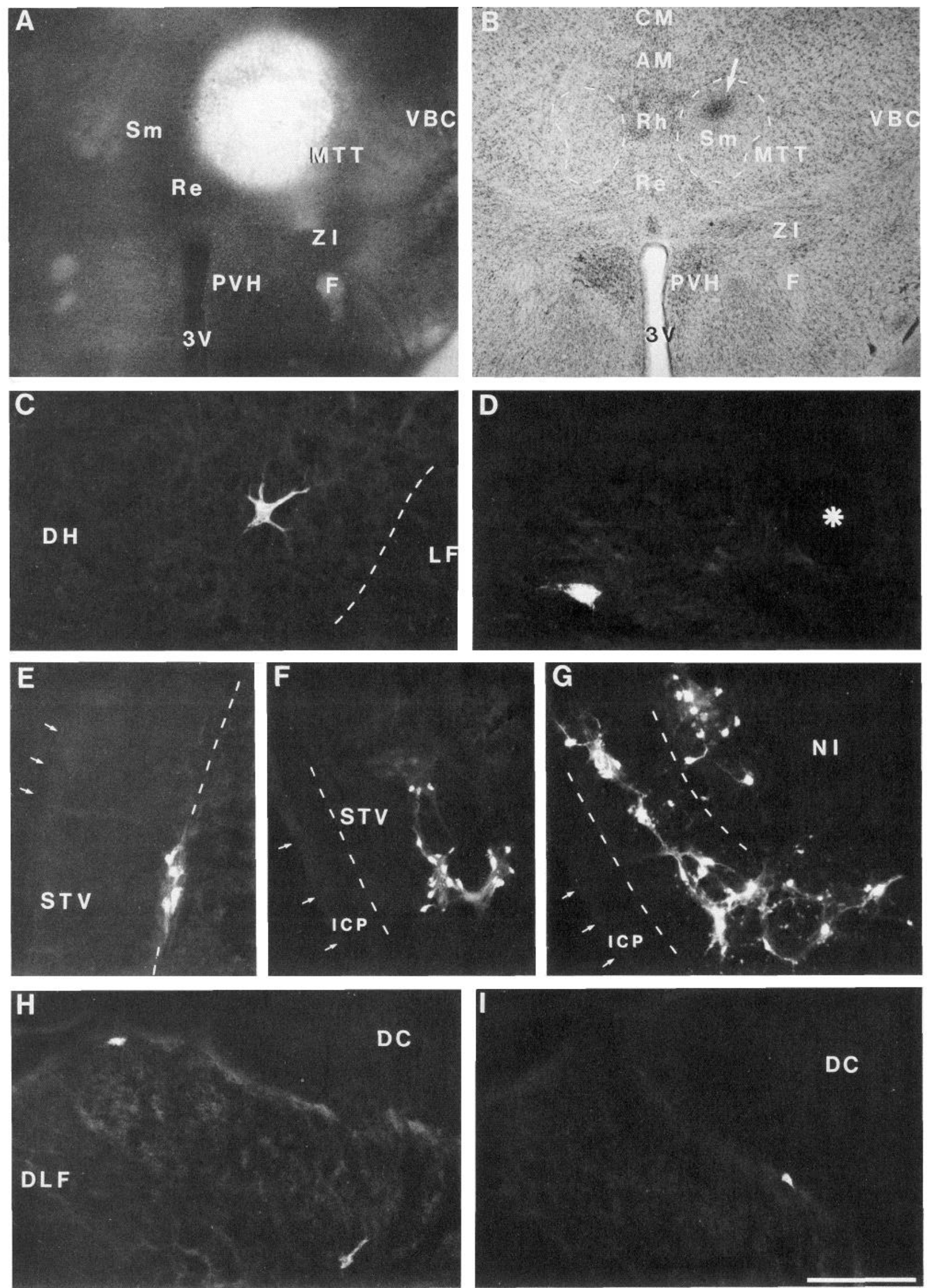
rons $(230)$ in the spinal cord was found in this rat, but none were seen in the marginal zone.

The mean number of labeled neurons in the spinal cords of rats Sm 1-6 was approximately 90 neurons (Table 1 ). ${ }^{1}$ More than $80 \%$ were located either in the deep dorsal horn $(51 \%$; Fig. $1 C)$ or intermediate zone/ventral horn $(30 \%)$. The area around the central canal contained $11 \%$ (Fig. $1 D$ ) and the lateral spinal nucleus/lateral cervical nucleus contained $7 \%$ of the labeled neurons. Fewer than $1 \%$ of the labeled neurons in the spinal cord were in the superficial dorsal horn. In the 6 rats, a total of 4 neurons was labeled in the superficial dorsal horn. Each of these 4 neurons was in the marginal zone; none were in substantia gelatinosa. The largest number in the superficial dorsal horn in any single rat was $2(\mathrm{Sm} 5)$. In 3 of the 6 cases (Sm4-6), the halo of FG crossed the midline. The number and distribution of labeled neurons in these rats did not appear to differ from those that received a unilateral injection, indicating that the FG that crossed the midline apparently did not label a large number of neurons.

The cervical segments contained approximately $74 \%$ of the retrogradely labeled neurons, $10 \%$ were in the thoracic segments, and $16 \%$ were in the lumbosacral segments. Approximately $64 \%$ of the labeled neurons in the spinal cord were found contralateral to the injection site in the 3 cases (Sm 1-3) in which the tracer did not cross the midline.

\section{Injections of $F G$ into areas near $S m$}

In 13 rats, the necrotic core of the injection missed the dorsal half of Sm (NonSm1-13; Fig. 4, $A-D$ ). These injections were approximately the same size as those into $\mathrm{Sm}$ and were located in one or more of the following structures: rhomboid nucleus, nucleus reuniens, ventral nucleus reuniens, zona incerta, central medial nucleus, paracentral nucleus, ventral lateral nucleus, ventral medial nucleus, anterior medial nucleus, prerubral field, an unnamed area in the ventromedial thalamus (ventral to nucleus reuniens, and dorsal to the third ventricle) or the mammillothalamic tract (Paxinos and Watson, 1986). These injections surrounded Sm anteriorly, posteriorly, dorsally, ventrally, medially, and laterally. The results of these injections are included for 2 main reasons. First, since our data indicate that neurons in the marginal zone of the spinal cord do not appear to project to $\mathrm{Sm}$, it is possible that they may project to an area near Sm. These injections should reveal the presence of such a projection if it exists. Second, little is known about the cells of

\footnotetext{
' The mean of 90 labeled neurons was based on all 6 cases. As mentioned previously, the injections in $\mathrm{Sm} 6$ included not only $\mathrm{Sm}$, but also spread into other nuclei, including the central medial nucleus (Fig. $3 E$ ). In contrast, cases Sm 1-5 received single injections that were primarily restricted to $\mathrm{Sm}$. The mean number of labeled neurons in the 18 spinal segments in Sm1-5 was $62 \pm 44$.
}

origin of spinothalamic tract (STT) projections to these small thalamic areas.

Each of these injections retrogradely labeled neurons in the spinal cord. The total number of neurons counted in the spinal cord of each rat is presented in Table 2. The number and distribution of labeled neurons was similar to that following injections into $\mathrm{Sm}$. Over two-thirds were located in either the deep dorsal horn (39\%) or intermediate zone/ventral horn (29\%). About 3\% were located in the superficial dorsal horn. Nearly half $(17 / 39)$ of the labeled neurons in the superficial dorsal horn in these cases were found in one ral (NonSm4). Approximately $62 \%$ were counted in cervical cord, $10 \%$ in thoracic cord, and $28 \%$ in lumbosacral cord.

Neurons in the caudal medulla were also labeled by injections into areas near Sm (Table 2). In 5 (NonSm3, 7, 9, 10, 13) of the 13 animals, labeled neurons were seen primarily in the superficial nucleus caudalis in a pattern similar to that seen following injections into $\mathrm{Sm}$. A mean number of approximately 45 neurons was counted in nucleus caudalis in these 5 animals. However, the locations of the injections in these cases (Fig. 4, $B-D$ ) revealed no obvious similarities to explain the pattern of labeled neurons. In the other 8 cases, fewer neurons were labeled (approximately 10 in each case) within nucleus caudalis.

\section{Injections of $F G$ inlo ventrobasal complex or posterior thalamic group}

Our injections into or near Sm consistently labeled a relatively small number of neurons in the spinal cord. To determine whether the techniques we used were capable of labeling large numbers of neurons, iontophoretic injections of FG were made into the $\mathrm{VBC}$ or Po of 6 rats. These areas are known to receive a dense projection from the spinothalamic tract (Lund and Webster, 1967; Mehler, 1969; Zemlan et al., 1978; Peschanski et al., 1983; Ma et al., 1986). The injection parameters were identical to those used to inject $\mathrm{Sm}$.

In 3 rats, the injection sites were located in anterior $\mathrm{VBC}$ at approximately the same anterior-posterior level as the injections into Sm. The diameters of the necrotic cores of the injections ranged from approximately 470 to $885 \mu \mathrm{m}$. The diameters of the injections including the halo varied from 1.0 to $1.6 \mathrm{~mm}$. Therefore, the sizes of the injection sites were similar to those of injections into $\mathrm{Sm}$.

An example of an injection into the anterior VBC is illustrated in Figure $5 \mathrm{~A}$. Many neurons were retrogradely labeled in the caudal medulla (379) and spinal cord (607) following this injection (Fig. 5, B, C). Labeled neurons within the spinal cord were concentrated in the deep dorsal horn of $\mathrm{C} 1-2$ and the lumbar cord.

In each of the 3 rats that received injections into $\mathrm{VBC}$, a large

Figure 1. Photomicrographs of an iontophoretic injection of FG into Sm and labeled neurons in the spinal cord and caudal medulla. $A$, Darkfield photomicrograph of an injection of $F G$ into $\mathrm{Sm}(\mathrm{Sml}) . B$, Bright-field photomicrograph of the same section after counterstaining with cresyl violet. Arrow indicates the core of the injection, and dashed line indicates the approximate outline of Sm. $C-G$, FG-labeled neurons following injections into Sm. $C$, Ipsilateral deep dorsal horn of C1-2. Dashed line represents the border between the lateral reticulated area of $D H$ and $L F$. $D$, Contralateral area around the central canal of C7-8. Asterisk indicates the location of the central canal. $E$, Contralateral superficial nucleus caudalis. Dashed line indicates the border between nucleus caudalis and $S T V$. In $E-G$, arrows indicate the lateral edge of the brainstem. $F$ Contralateral superficial nucleus caudalis near the border with nucleus interpolaris. These labeled neurons were located in the ventrolateral area of nucleus caudalis just medial to the $S T V$. Dashed line indicates the border between $S T V$ and $I C P$. G, Contralateral $N I$. Labeled neurons were located ventrolaterally both within $N I$ and the spinal trigeminal tract, which is the area between the dashed lines. $H$ and $I$, FG-labeled neurons following an injection near the border between the VBC and Po. $H$, Contralateral superficial dorsal horn and deep dorsal horn of C7-8. $I$, Contralateral superficial dorsal horn of C4-5. For abbreviations, see the Appendix. Scale bar, $1 \mathrm{~mm}$ for $A$ and $B ; 0.2 \mathrm{~mm}$ for $C$ and $E-I ; 0.1 \mathrm{~mm}$ for $D$. 
A
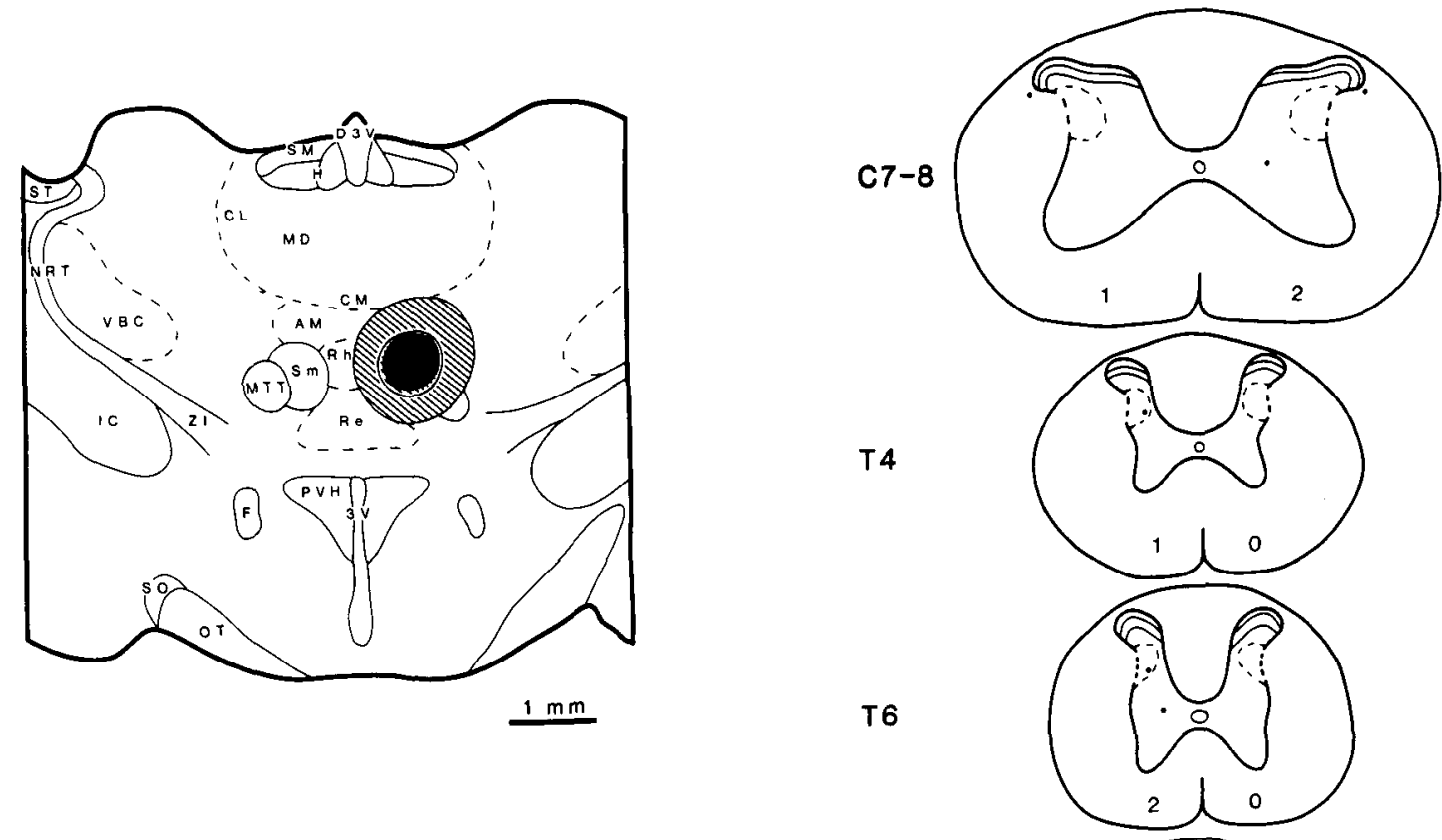

B

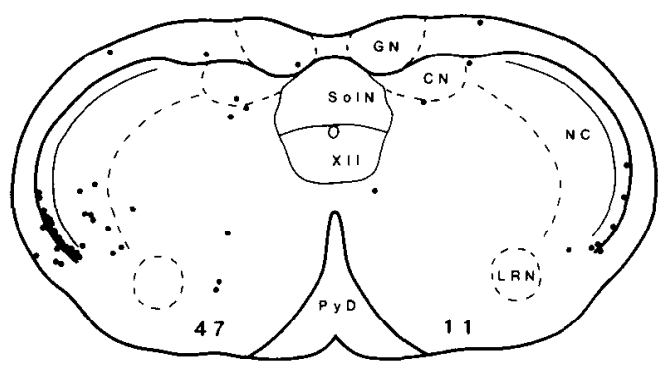

T8
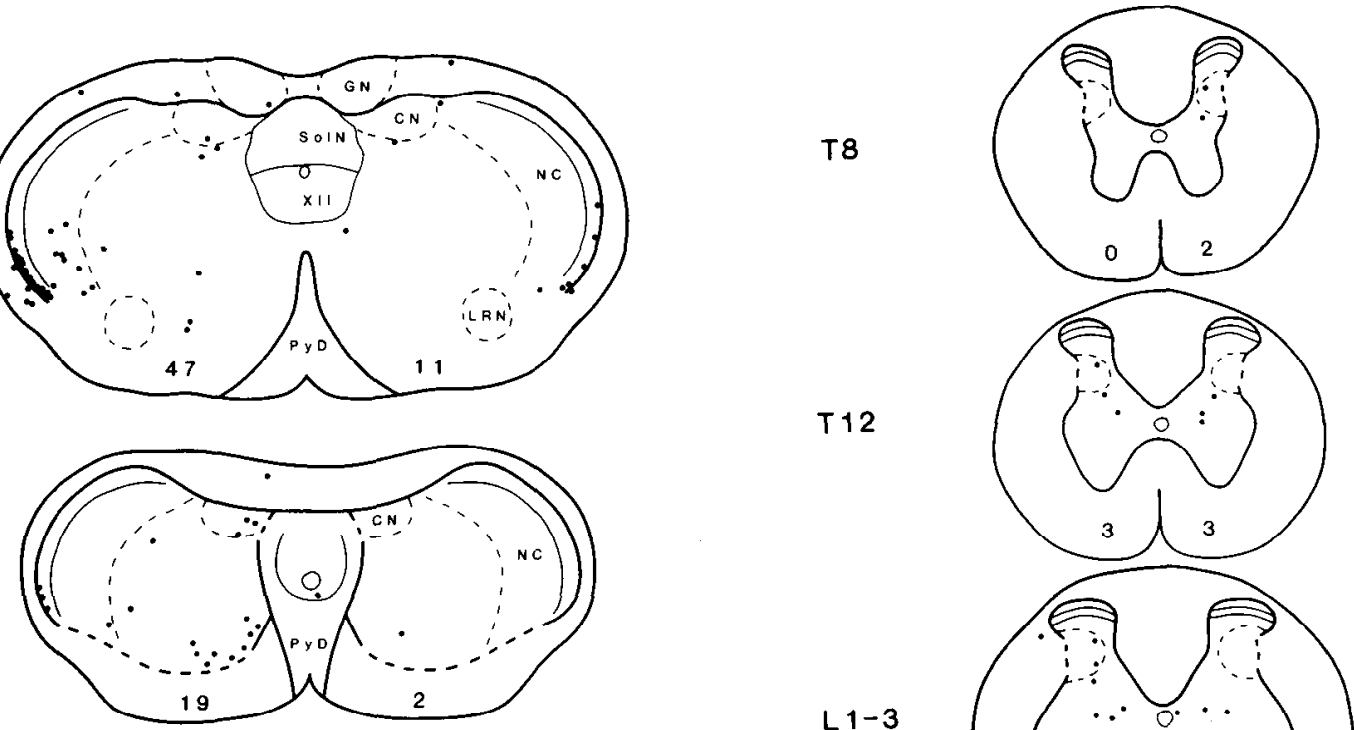

T12

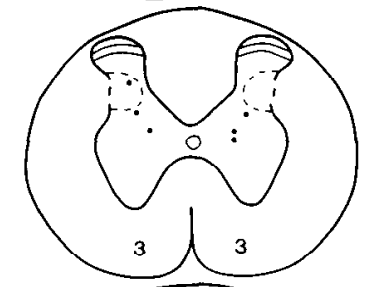

L 1-3
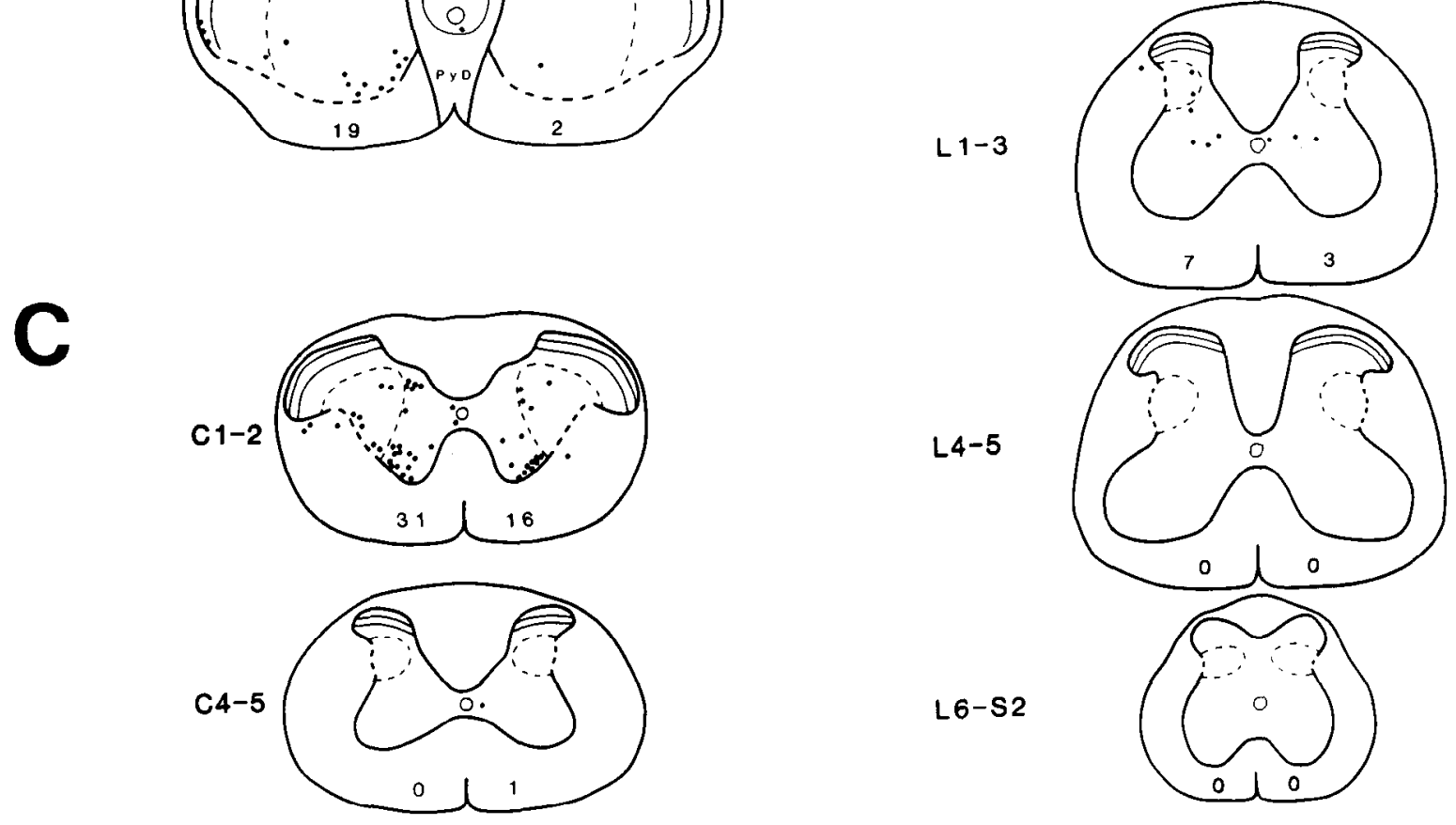

Figure 2. Reconstruction of an iontophoretic injection of FG into nucleus submedius and locations and numbers of retrogradely labeled neurons in alternate sections of the caudal medulla and 18 spinal cord segments $(S m 1)$. $A$, The necrotic core of the injection was restricted to $S m$ and is represented by the black area. The halo of FG surrounding the core is shown by the cross-hatched area. The approximate location of $S m$ on the 
number of labeled neurons was counted (419 \pm 168$)$. Retrogradely labeled neurons were found primarily in $\mathrm{C} 1-2(45 \%)$ and in the lumbar cord (52\%; Fig. 5C). ${ }^{2}$ Most labeled neurons were in the deep dorsal horn (74\%) and intermediate zone/ ventral horn (14\%). Approximately $97 \%$ of the labeled neurons were located contralateral to the injection site. Retrogradely labeled neurons in the caudal medulla were restricted primarily to the contralateral dorsal column nuclei (Fig. $5 B$ ). In 2 of the animals, no labeling was present in either the superficial or deep nucleus caudalis. In the third case, 5 neurons were counted in the contralateral superficial nucleus caudalis.

In 3 rats $(\mathrm{Po} / \mathrm{VBC} 1-3)$, an area near the border between the posterior thalamic group and the caudal ventrobasal complex was injected iontophoretically with FG. In the best case $(\mathrm{Po} /$ VBC1; Fig. $6 A$ ), over 700 neurons were retrogradely labeled throughout the length of the spinal cord (Fig. $6 \mathrm{C}$ ). Many neurons (122) were labeled in the marginal zone. Most were found throughout the cervical cord (Fig. 1, $H, I$ ); a few were also seen in lumbar segments (Fig. 6C).

A mean number of $387 \pm 325$ neurons was labeled in the three cases. Approximately $15 \%$ of the labeled neurons were located in the marginal zone. Fifty percent were found in the deep dorsal horn. Most of the labeling occurred in the cervical (82\%) cord. Approximately $93 \%$ of the labeled neurons were found contralateral to the injection site. The distribution of labeled neurons in the caudal medulla differed from that following injections into $\mathrm{Sm}$. A larger number of ncurons in deep nucleus caudalis were labeled, and those in superficial nucleus caudalis were concentrated in the dorsal half of the nucleus (Fig. $6 B$ ). Labeled neurons were also present in the reticular formation and the dorsal column nuclei.

\section{Injections of Fast blue into Sm}

Craig et al. (1989a) reported that the fluorescent tracer Fast blue effectively labels small spinothalamic tract neurons in the marginal zone. Therefore, we made pressure injections of Fast blue into $\mathrm{Sm}$ of 3 rats $(\mathrm{Sm} 7-9)$. One rat $(\mathrm{Sm} 7)$ was allowed to survive $4 \mathrm{~d}$; the other $2(\mathrm{Sm} 8,9)$ survived $11 \mathrm{~d}$. An example of a pressure injection of Fast blue into $\mathrm{Sm}(\mathrm{Sm} 8)$ is illustrated in Figure $7 \mathrm{~A}$. The necrotic core of the injection was centered in the dorsal half of Sm. However, there was spread of the halo dorsally along the pipette track into several areas, including the central medial nucleus, the medial dorsal nuclcus, the habenula, and the dorsal

\footnotetext{
${ }^{2}$ Following each of these injections into the anterior VBC, many neurons were labeled in lumbar segments. Far fewer neurons were labeled in thoracic segments and the cervical enlargement (Fig. 5C). This organization is consistent with the known somatotopic input to the VBC from STT neurons; those in the lumbar cord project mainly to the anterior VBC, whereas those in the cervical cord project primarily to caudal VBC (Peschanski et al., 1983; Ma et al., 1986). However, in all cases, large numbers of neurons were also labeled in the rostral 2 cervical segments. The organization of the projections from these segments and the large, often whole-body receptive fields of many of the neurons in these segments (Carstens and Trevino, 1978) are not consistent with a simple somatotopic scheme. It should also be pointed out that each of our injections into the anterior VBC labeled many neurons in the contralateral cuneate nucleus (Fig. $5 B$ ), but failed to label neurons in the cervical enlargement (Fig. $5 \mathrm{C}$ ). To our knowledge, this is the first indication in rats that the projections from the cuneate nucleus and STT neurons in the cervical enlargement may not overlap completely.
}

third ventricle. The injection spread approximately $2.0 \mathrm{~mm}$ rostrocaudally and included the entire anterior-posterior extent of $\mathrm{Sm}$. The halo of the injection extended approximately 500 $\mu \mathrm{m}$ beyond the anterior limit of $\mathrm{Sm}$ and $100 \mu \mathrm{m}$ beyond the posterior limit.

Following this pressure injection of Fast blue, labeled neurons were seen bilaterally in the caudal medulla. The locations and rostrocaudal distribution of labeled neurons in superficial nucleus caudalis were similar to that described following iontophoretic injections of FG into $\mathrm{Sm}$. Many labeled neurons were locatcd in superficial nucleus caudalis near the junction with nucleus interpolaris (Fig. 7B). In contrast, more labeled neurons were seen in the reticular formation after injections of Fast blue and some were also found in the nucleus of the solitary tract and the hypoglossal nucleus.

A total of 441 neurons was labeled throughout the length of the spinal cord in Sm8 (Fig. 7C; Table 3). The majority of labeled neurons were located in the deep dorsal horn $(46 \%)$ and intcrmediate zone/ventral horn $(28 \%)$. Three labeled neurons $(<1 \%)$ were found in the marginal zone in this case. Labeled neurons were also found in the area around the central canal, the lateral spinal nucleus, and the lateral cervical nucleus. Approximately $56 \%$ of the labeled neurons in the spinal cord were found contralateral to the injection site.

The total number of neurons labeled in nucleus caudalis and the spinal cord for each of the 3 rats that received injections of Fast blue is summarized in Table 3. Over $70 \%$ of the labeled neurons in the spinal cord were located in the deep dorsal horn and intermediate zone/ventral horn. The area around the central canal and the lateral spinal nucleus/lateral cervical nucleus each contained approximately $13 \%$ of the labeled neurons. Less than $2 \%$ were located in the superficial dorsal horn. Approximately $62 \%$ of the labeled neurons were in the cervical cord, $10 \%$ were in the thoracic cord, and $28 \%$ were in the lumbosacral cord.

\section{Discussion}

Following small iontophoretic injections of FG into nucleus submedius of 6 rats, only a small number of retrogradely labeled neurons was observed in the spinal cord in each case. More than $80 \%$ of the neurons labeled were found in the deep dorsal horn or intermediate zone/ventral horn. Surprisingly, labeled neurons were virtually absent in the marginal zone throughout the length of the spinal cord.

The results of larger pressure injections of Fast blue into $\mathrm{Sm}$ of three rats confirmed those following small iontophoretic injections of FG. Again, many labeled neurons in the spinal trigeminal nucleus were found in superficial nucleus caudalis near the border with nucleus interpolaris. 'The distribution of labeled neurons in the spinal cord was also remarkably similar to that seen following injections of FG. Most of the labcled neurons were found in the deep dorsal horn and intermediate zone/ ventral horn. Following injections of Fast blue, few neurons were seen in the marginal zone. In fact, in the 9 rats that received injections of either FG or Fast blue into Sm, a total of only 16 labeled neurons was counted in the marginal zone in over 5300 sections of spinal cord that were examined.

right side is outlined. Note that in this and all subsequent figures, dashed lines represent approximate locations of boundaries and nuclei that were frequently difficult to determine specifically. Scale bar, $1 \mathrm{~mm}$. B. Caudal medulla at level slightly posterior to obex (top) and approximately 1 mm posterior to obex (bottom). The right side is ipsilateral to the injection in all figures. $C$, Each labeled neuron in the spinal cord in alternate sections is indicated by a dot. The total number of labeled neurons found in each side of the indicated segments in alternate sections is shown. 
A

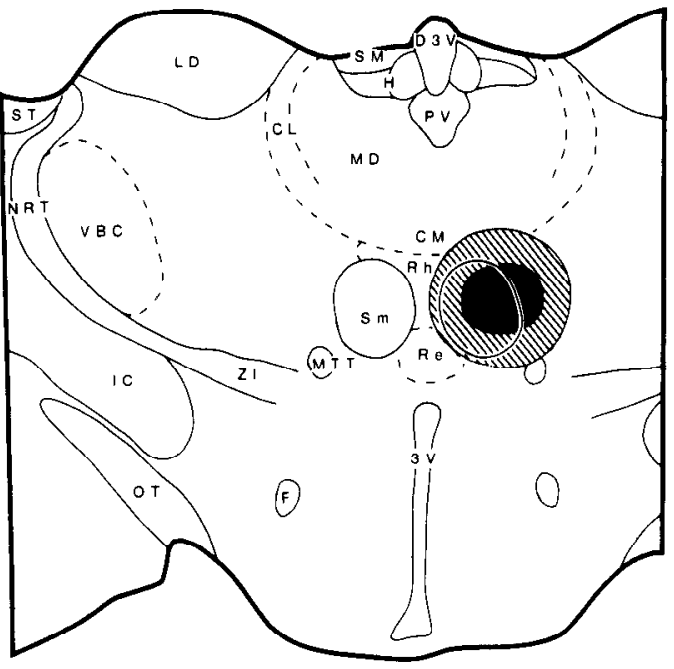

B

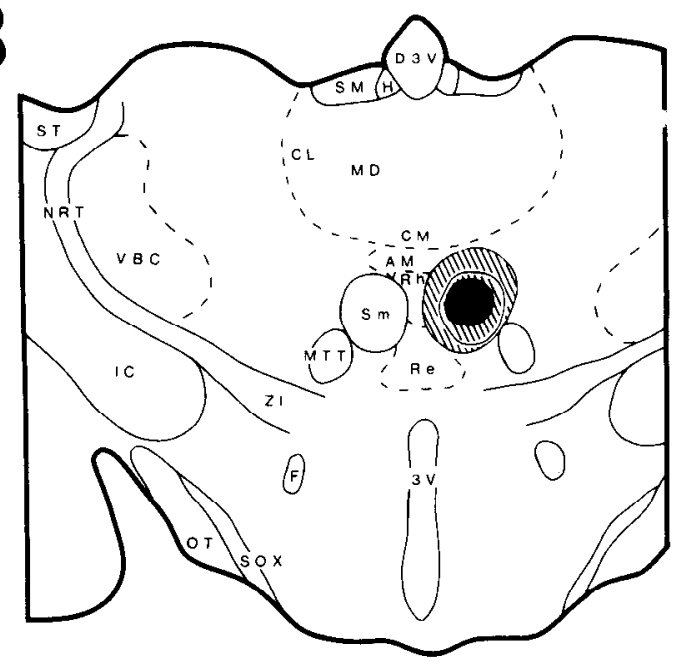

C

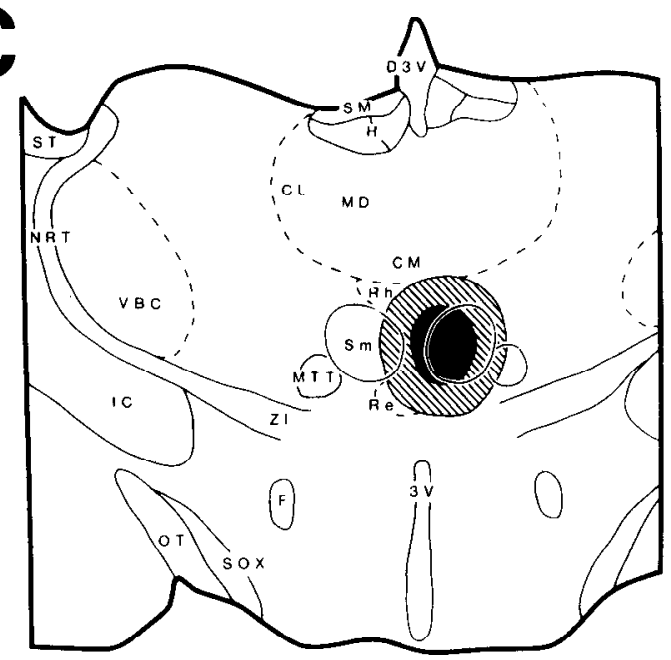

D

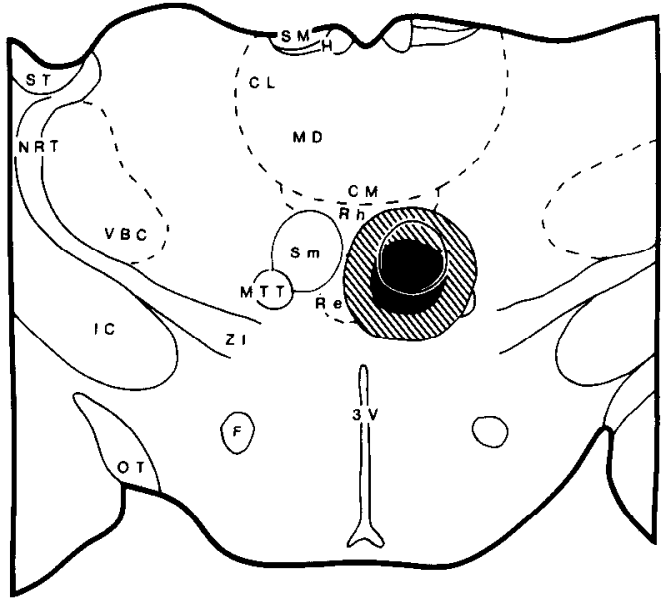

$\mathbf{E}$

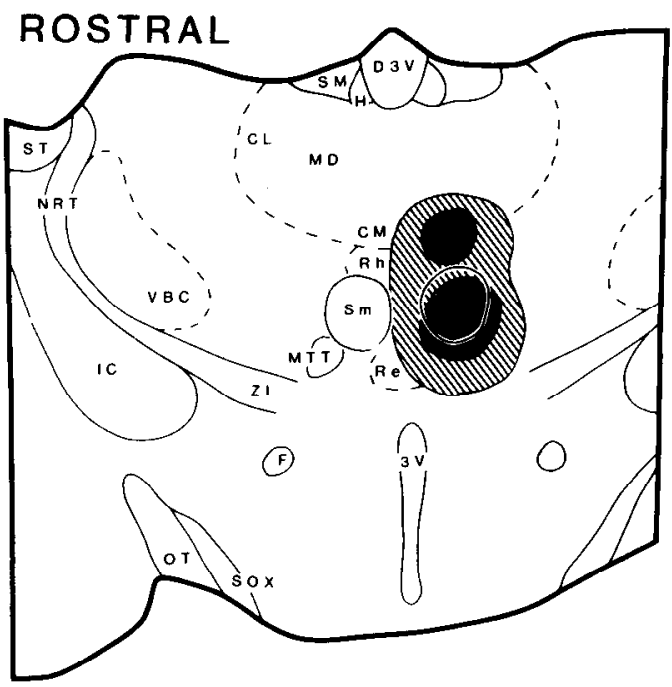

CAUDAL

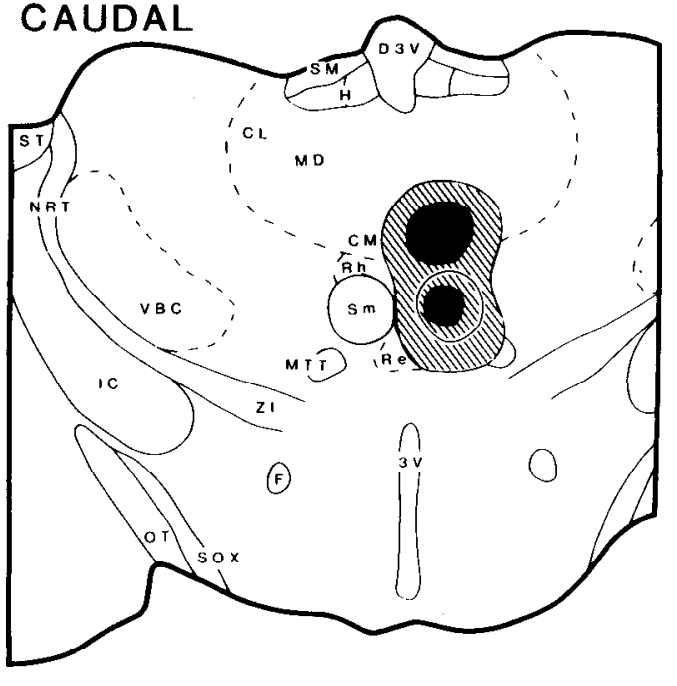

$1 \mathrm{~mm}$

Figure 3. Drawings of injections of FG into nucleus submedius $(\mathrm{Sm} 2-6)$. A-E, Sm2, 3, 4, 5, and 6, respectively. Scale bar, $1 \mathrm{~mm}$. 
A

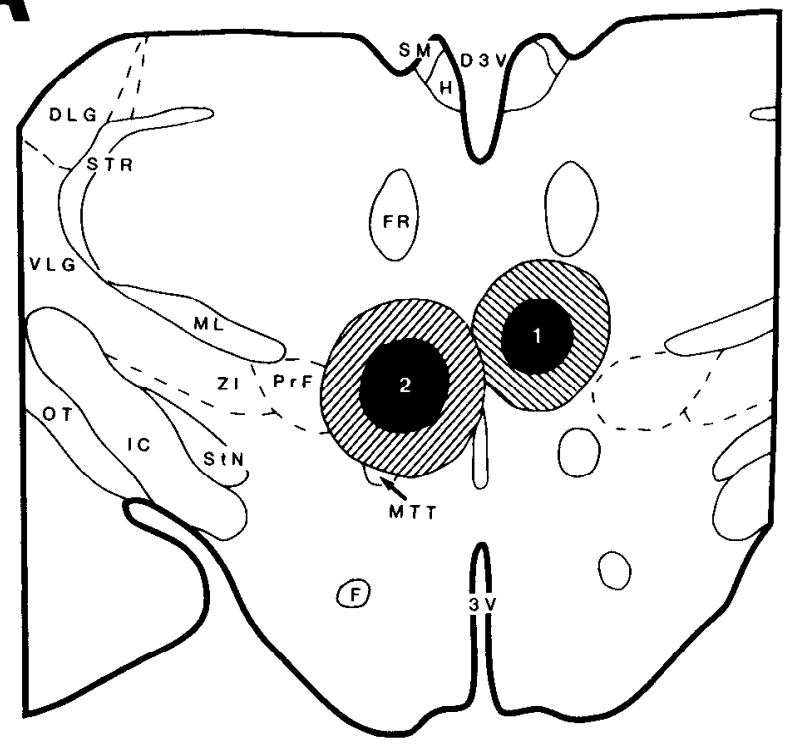

B

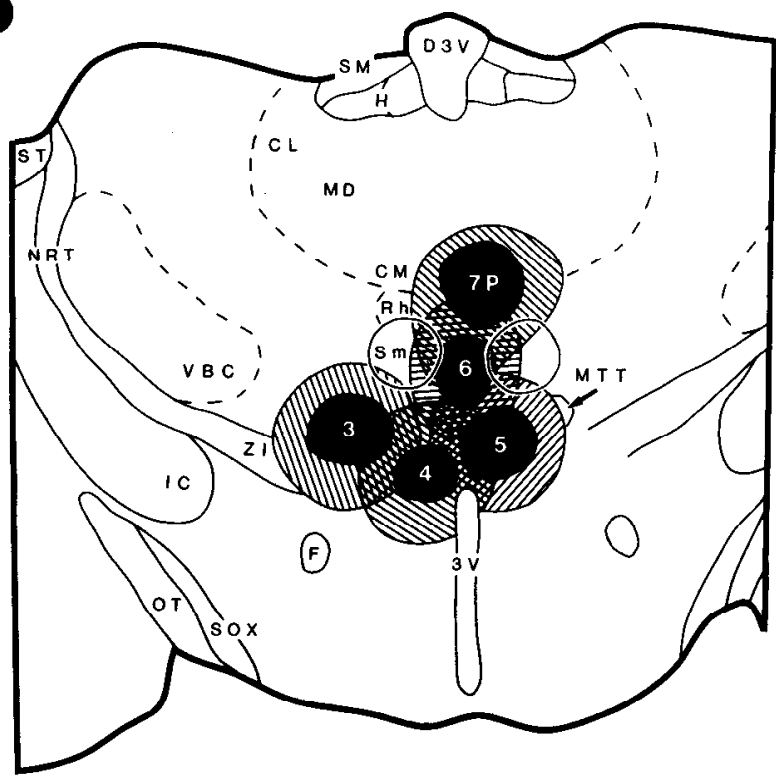

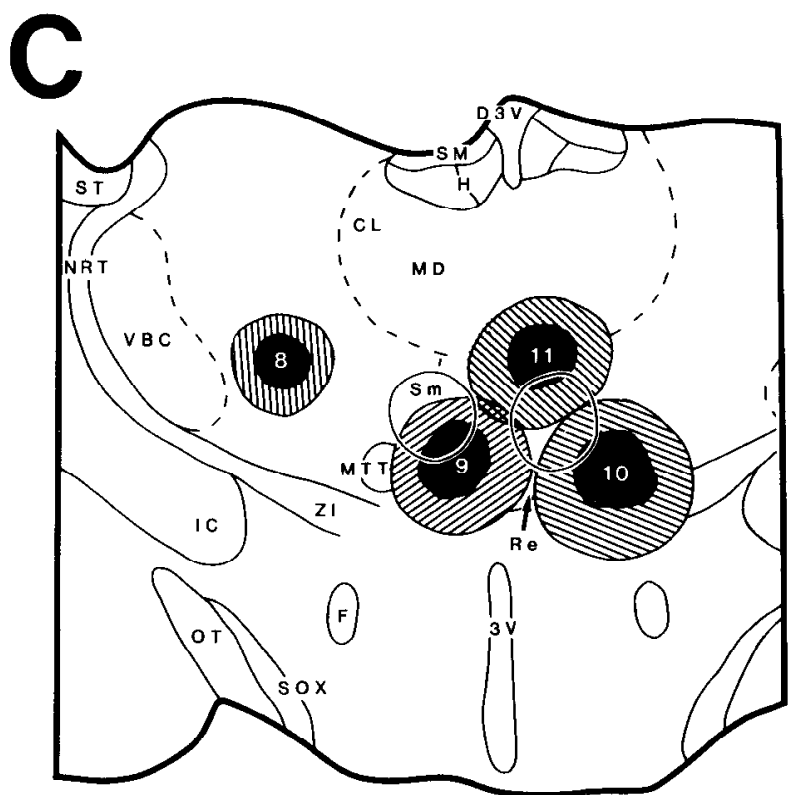

D

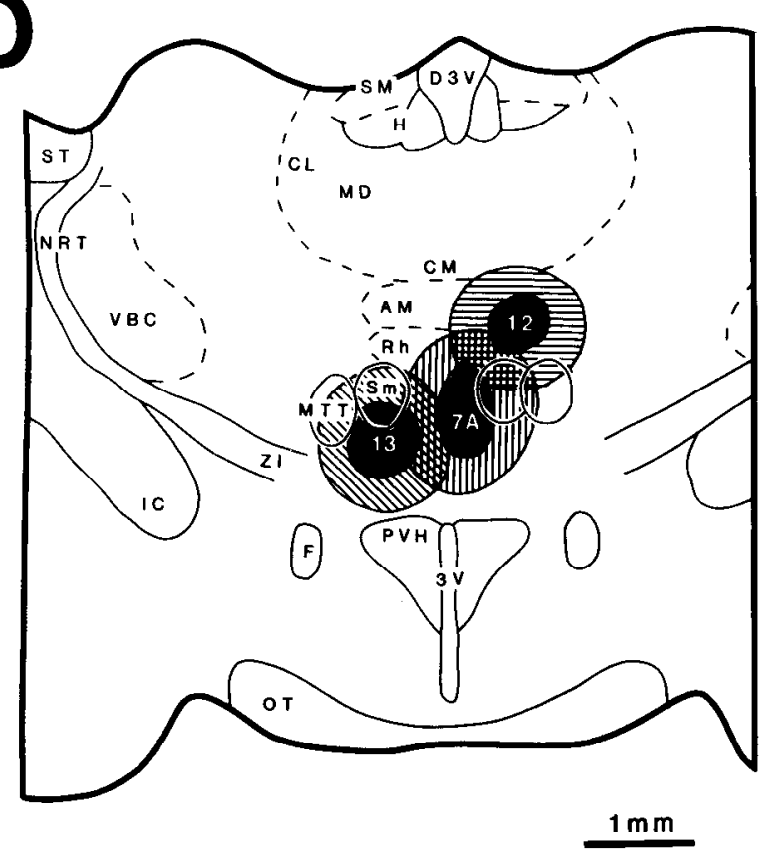

Figure 4. Drawings of injections of FG into areas near nucleus submedius. $A-D$, Caudal to rostral. Numbers in the center of each injection represent the case number (NonSm1-13). In NonSm7, an injection was made at 2 different anterior-posterior coordinates ( $7 A$ and $7 P$ ). Scale bar, $1 \mathrm{~mm}$.

In contrast, within the caudal medulla, many neurons were labeled in the superficial dorsal horn of rostral nucleus caudalis following either injections of FG or Fast blue. Many labeled neurons were also seen in nucleus interpolaris. Dostrovsky et al. (1989) also reported that many neurons were retrogradely labeled in nucleus interpolaris following iontophoretic injections of WGA-HRP into Sm of rats.

In 13 rats, our injections of $\mathrm{FG}$ missed $\mathrm{Sm}$. These injections were found in surrounding nuclei, including the rhomboid nucleus, nucleus reuniens, and the ventromedial nucleus. In each case, small numbers of neurons were labeled in the spinal cord. Again, the majority of labeled neurons were located in the deep dorsal horn and intermediate zone/ventral horn and very few neurons were labeled in the marginal zone. These results are consistent with previous studies in rats in which injections of HRP or fluorescent retrograde tracers into the medial thalamus labeled neurons that were located almost exclusively in deep areas of the gray matter (Giesler et al., 1979, 1981; Kevetter and Willis, 1983; Menetrey et al., 1984; Coffield and Miletic, 1987; Nahin, 1988). Thus, based on these studies using a variety 
A

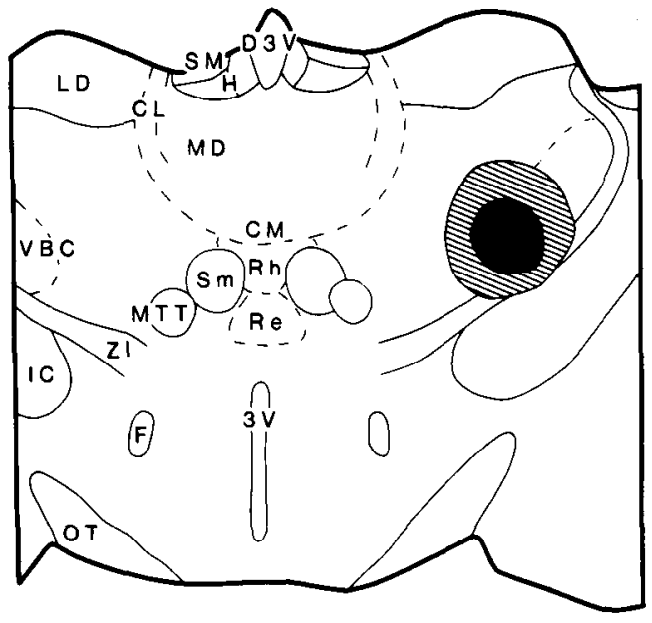

T4

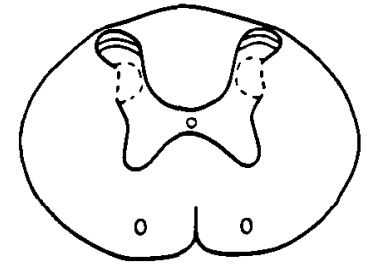

T6

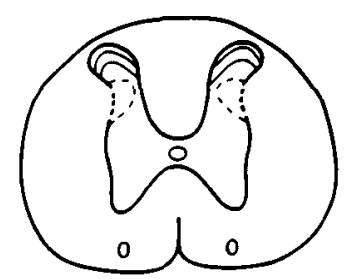

$1 \mathrm{~mm}$

T8

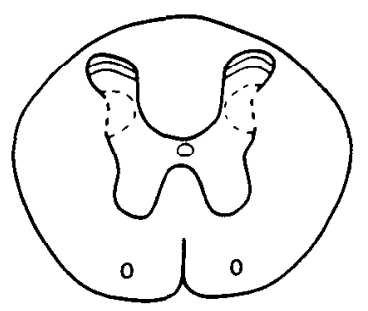

B
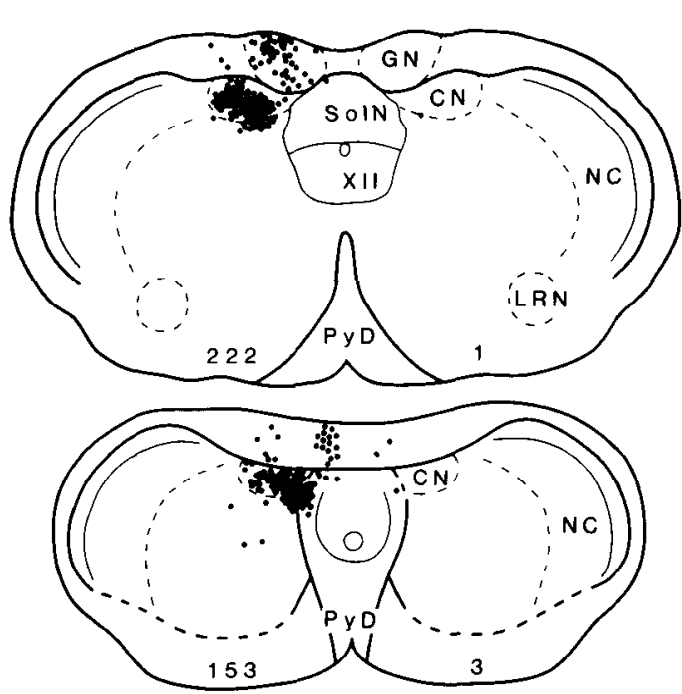

T12

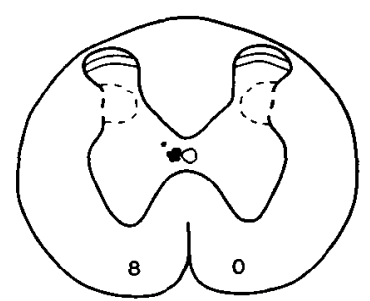

L 1-3
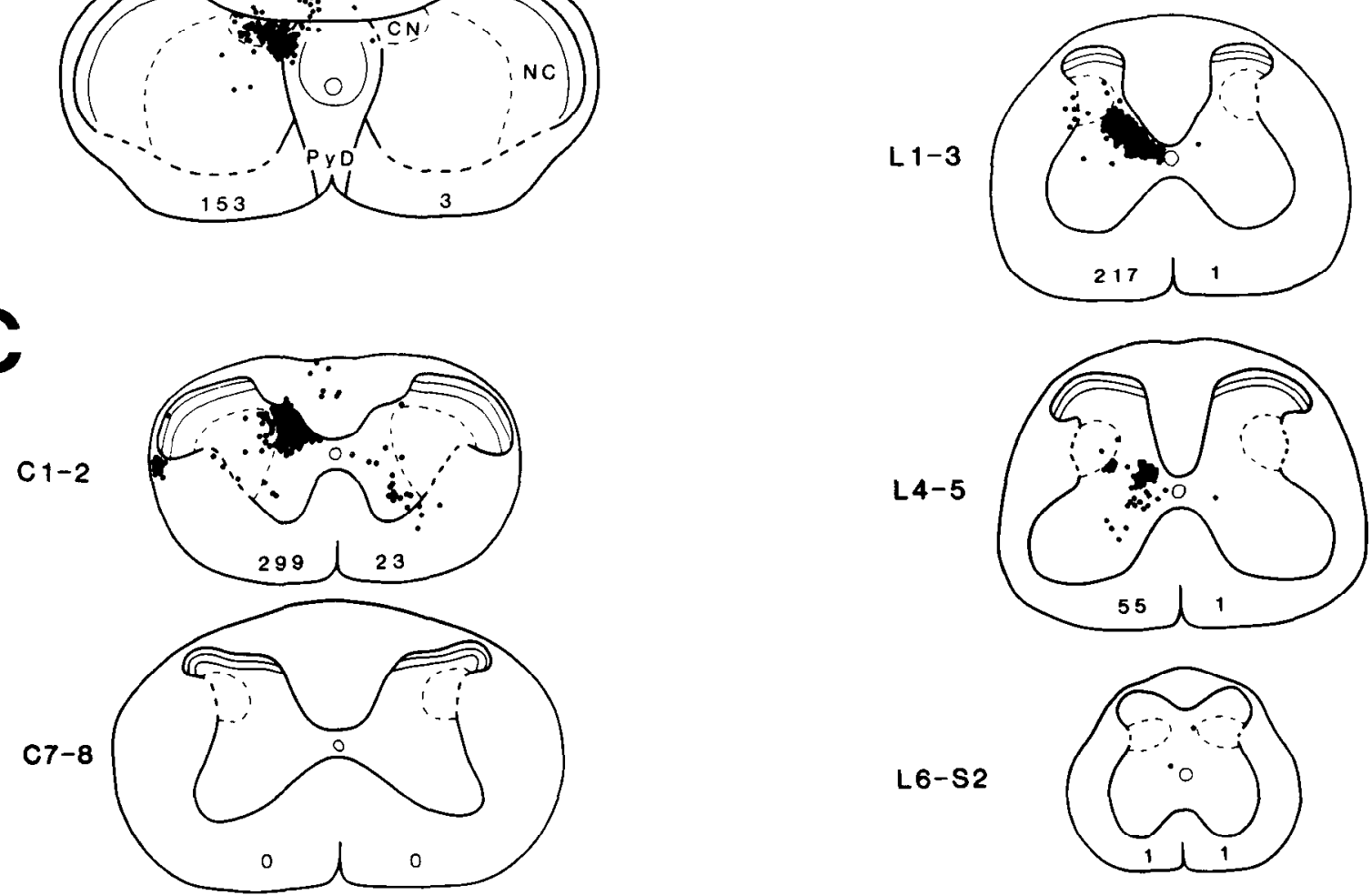

L6-S2

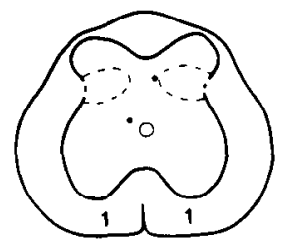

Figure 5. Reconstruction of an injection of FG into the ventrobasal complex and the locations and numbers of neurons retrogradely labeled in alternate sections of the caudal medulla and spinal cord. $A$, Injection site. Scale bar, $1 \mathrm{~mm}$. $B$, Locations and numbers of labeled neurons in the caudal medulla. $C$, Locations and numbers of neurons labeled in 16 spinal cord segments. C4-5 is not included but contained one neuron in SDH. 

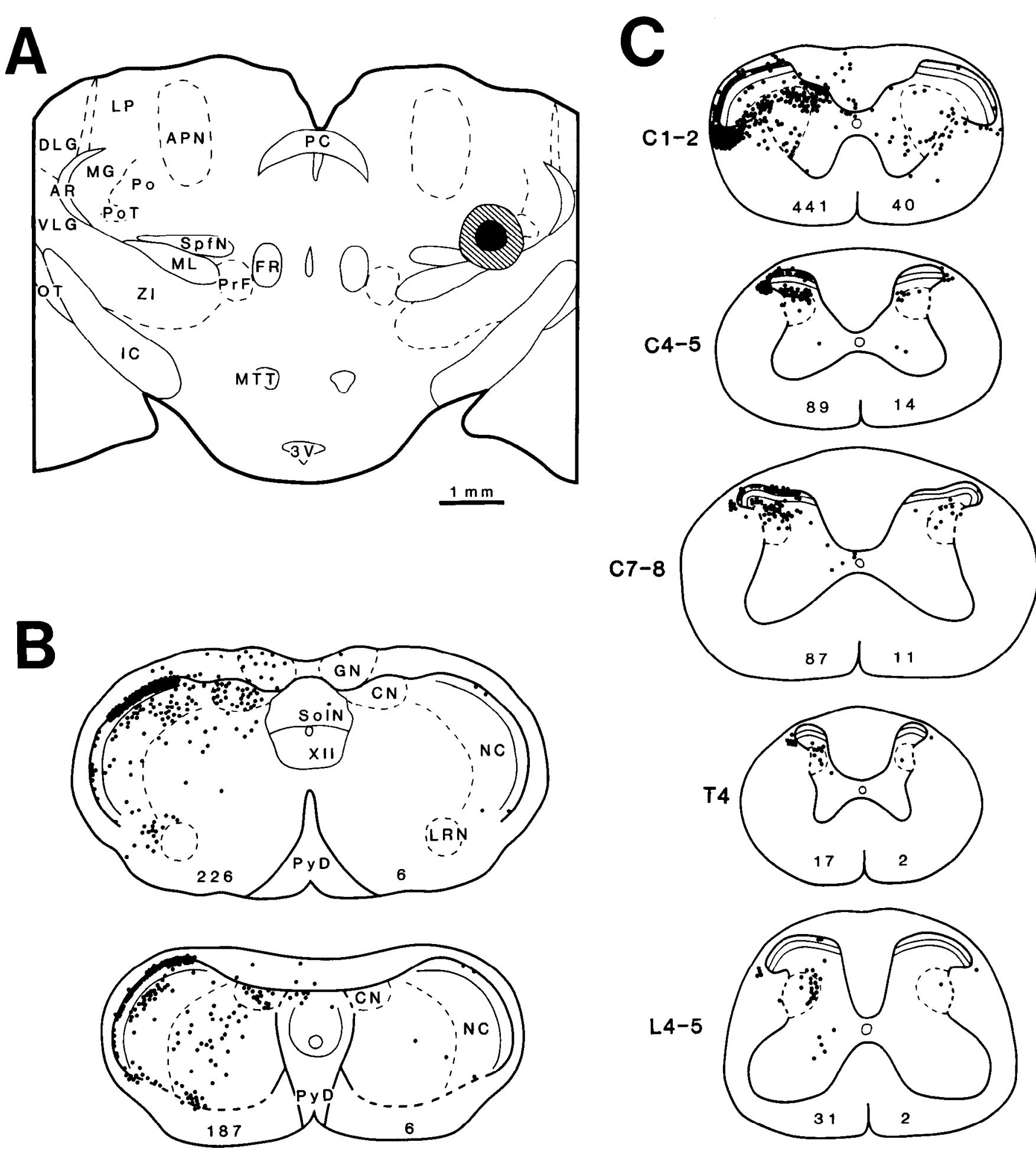

Figure 6. Reconstruction of an injection of FG into the area of the posterior thalamic group and the locations and numbers of neurons retrogradely labeled in alternate sections of the caudal medulla and spinal cord. $A$, Injection site. Scale bar, $1 \mathrm{~mm} . B$, Locations and numbers of labeled neurons in the caudal medulla. $C$, Locations and numbers of labeled neurons in 9 representative spinal cord segments. T6, T8, T12, L1-3, and L6-S2 are not included but contained $1,1,5,13$, and 1 labeled neuron(s), respectively.

of tracers, it appears that there is a small, diffuse projection from neurons located in deeper areas of the spinal cord gray matter to $\mathrm{Sm}$ and the nuclei near it. Almost no neurons in the marginal zone of the spinal cord appear to project to this region of the thalamus in rats.

A recent electrophysiological study in rats (Dostrovsky and
Guilbaud, 1990) has shown that there are nociceptive neurons throughout the medial thalamus, including the medial dorsal nucleus, anterior medial nucleus, ventral medial nucleus, ventral lateral nucleus, and the intralaminar nuclei. Within these nuclei, the percentage of nociceptive neurons is similar to that found in Sm. In addition, many neurons in these nuclei have 

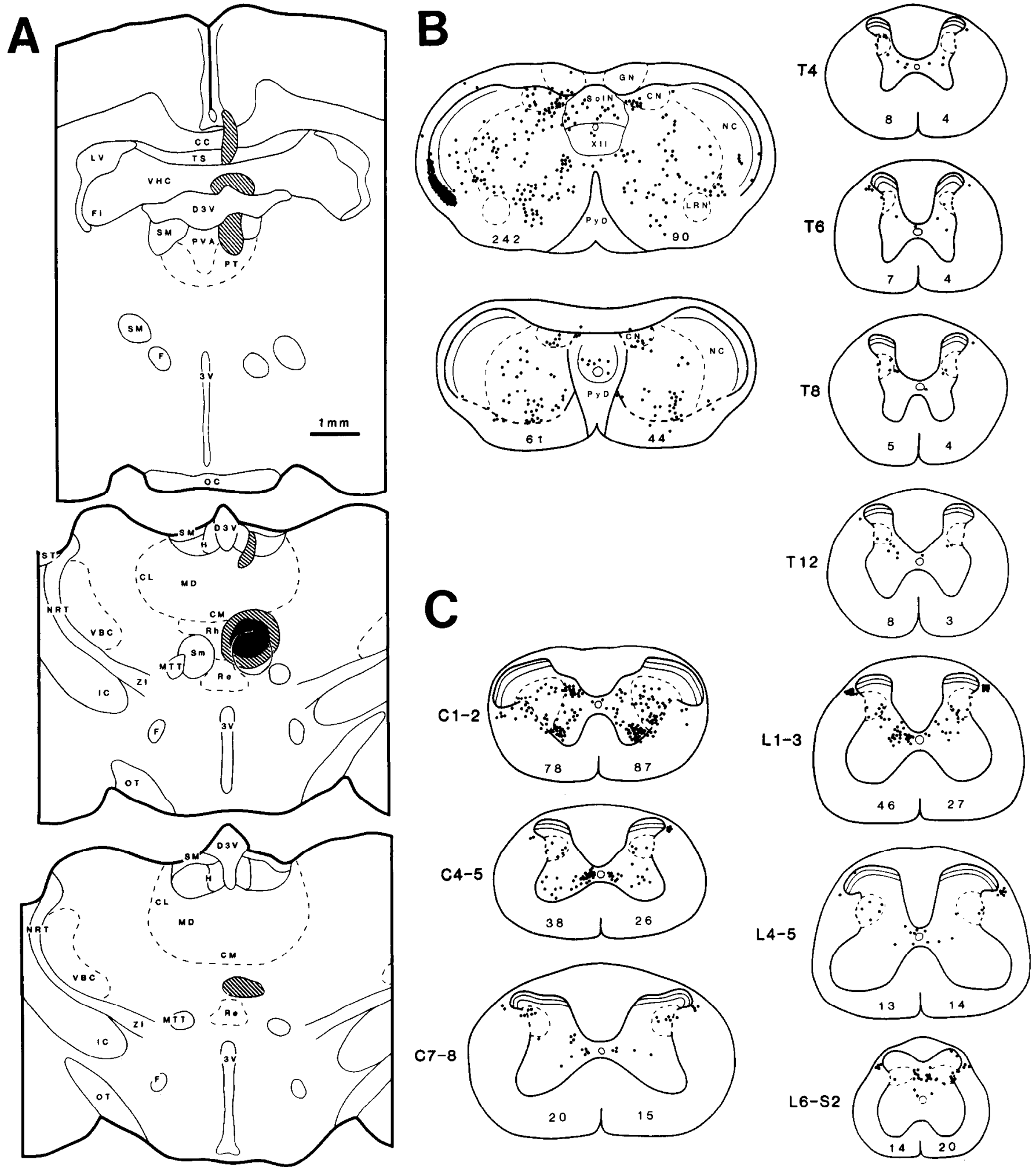

Figure 7. Reconstruction of a pressure injection $(\operatorname{Sm} 8)$ of Fast blue into nucleus submedius and locations and numbers of retrogradely labeled neurons in alternate sections of the caudal medulla and 18 spinal cord segments. $A$, Injection site. Anterior limit of the injection is shown at $t o p$ and posterior limit at the bottom. Scale bar, $1 \mathrm{~mm}$. $B$, Locations and numbers of labeled neurons in the caudal medulla. $C$, Locations and numbers of labeled neurons in the spinal cord.

response characteristics and receptive fields that are virtually identical to those of neurons in Sm (Dostrovsky and Guilbaud, 1988, 1990). Therefore, neurons within $\mathrm{Sm}$ and several other medial thalamic nuclei have similar response characteristics and receive similar projections from the spinal cord.

\section{Technical considerations}

Our iontophoretic injections of FG into Sm consistently labeled only a small number $(<100)$ of neurons in the spinal cord and almost none in the marginal zone. These results might suggest 
that our tracing techniques were inadequate for labeling all neurons that project to $\mathrm{Sm}$. For the following reasons, we believe the techniques we used were appropriate and effective: (1) Very similar results were obtained following injections of 2 different fluorescent retrograde tracers, FG and Fast blue. These tracers appear to be among the most sensitive for labeling projection neurons in the spinal cord (Schmued and Fallon, 1986; Burstein et al., 1987, 1990a, b; Craig et al., 1989a, b). It has also been reported that Fast blue labels small neurons within the marginal zone more effectively than does HRP (Craig et al., 1989a). (2) Injections of FG into the ventrobasal complex that were similar in size to those into Sm labeled hundreds of neurons in the spinal cord. (3) Small iontophoretic injections of FG near the border between VBC and Po also labeled many neurons in the spinal cord, including more than 100 in the marginal zone in the most effective of the 3 cases.

The spinal and trigeminal inputs to nucleus submedius are somatotopically organized in cats and, to a lesser degree, in rats (Craig and Burton, 1981). Therefore, it is possible that we failed to label many neurons in the spinal cord because our injections missed the area of $\mathrm{Sm}$ that receives spinal input (i.e., the rostral region of the nucleus). We believe this is unlikely since each injection covered more than three-quarters of the rostrocaudal extent of Sm. In all cases, the injection spread anteriorly to the rostral limit of Sm. Also, the injections into $\mathrm{Sm}$ were centered at different anterior-posterior levels of the nucleus. No clear differences could be seen regarding the quantity or distribution of neurons labeled in these cases.

Craig et al. (1989b) have suggested that to achieve maximum labeling of lumbosacral neurons following injections of Fast blue in cats, survival periods of $1 \mathrm{~d} / \mathrm{cm}$ of transport are needed. Therefore, we allowed 2 rats $(\mathrm{Sm} 8,9)$ to survive $11 \mathrm{~d}$ following injections of Fast blue into $\mathrm{Sm}$ to determine if a larger number of neurons would be labeled in the marginal zone following this long survival time. This survival period should have allowed transport of the tracer to the lumbar cord, since the distance from the thalamus to the lumbar enlargement in rats is approximately $10-11 \mathrm{~cm}$. Following these fairly large injections, a greater total number of neurons was labeled throughout the length of the spinal cord, but there was no increase in the percentage of neurons labeled in the superficial dorsal horn. Fewer than $2 \%$ of the labeled neurons were in the marginal zone. Thus, in our experiments, the distribution of the locations of neurons projecting to $\mathrm{Sm}$ from the spinal cord was not altered by longer survival times.

The findings of Craig et al. (1989b) raise the possibility that other fluorescent tracers, including FG, might also require longer survival periods for adequate transport throughout the spinal cord. Following injections of FG into $\mathrm{Sm}$, rats were allowed to survive $3-5 \mathrm{~d}$. The distance from the thalamus to the cervical enlargement in rats is approximately $4-5 \mathrm{~cm}$. Therefore, these survival times of 3-5 d should have been more than adequate for the tracer to be transported through at least the cervical cord. If these survival periods were only sufficient to label marginal zone neurons in the cervical cord, it would be predicted that these neurons would be found predominantly in this region of the cord. Yet, only 2 of the 4 labeled neurons counted in the marginal zone of the spinal cord were located in the cervical segments. The other 2 were in the lumbar enlargement. Therefore, the distribution of labeled neurons in the marginal zone does not suggest that the survival times we used were insufficient for transport of the tracer to the lumbar cord. Finally, in previous studies using survival periods similar to those in the present study, FG labeled thousands of spinohypothalamic tract (Burstein et al., 1990a) and spinothalamic tract (Burstein et al., 1990 b) neurons throughout the length of the spinal cord, including hundreds within the marginal zone. Thus, the survival times used in this study appear to have been adequate.

\section{Other species}

In several respects, the input to $\mathrm{Sm}$ from the spinal cord and caudal medulla is similar in rats and cats. The numbers of neurons in the spinal cord projecting to Sm appear to be small in both species. In the 2 cases in the cat presented by Craig and Burton (1981), totals of 77 and 300 neurons were counted in the 15 spinal cord segments examined. The rostrocaudal distribution of labeled neurons in the spinal cord also appears to be similar in both species. The majority of labeled neurons are located in the upper cervical cord. In the present study, nearly $75 \%$ were in the cervical cord, and Craig and Burton (1981) also reported that their most restricted injections into $\mathrm{Sm}$ labeled neurons predominantly in the upper cervical cord. In both species, the number of neurons that project to $\mathrm{Sm}$ from the spinal trigeminal nuclei is greater than the number that project from the entire spinal cord. Also, in both rats and cats, the majority of neurons in nucleus caudalis that project to $\mathrm{Sm}$ are located in the marginal zone.

In contrast, the locations of neurons in the spinal cord projecting to $\mathrm{Sm}$ in rats and cats differ in several respects. In cats, the input to $\mathrm{Sm}$ originates predominantly from neurons in the marginal zone (Craig and Burton, 1981). However, the input to $\mathrm{Sm}$ from the spinal cord in rats arises almost exclusively from neurons deep in the dorsal horn or the intermediate zone/ventral horn. Menetrey et al. (1984) illustrated an injection of HRP into $\mathrm{Sm}$ and the neurons that it labeled in a single rat. The few labeled neurons were located deep in the lumbar dorsal horn. Craig and Burton (1981) also reported that there is a minimal ipsilateral projection to $\mathrm{Sm}$ from neurons in the spinal cord of cats. In the present study in rats, approximately $40 \%$ of the neurons labeled by injections into $\mathrm{Sm}$ were in the ipsilateral spinal cord. Peschanski et al. (1983) reported that injections of WGA-HRP into the spinal cord of rats anterogradely labels spinothalamic tract axons bilaterally in Sm. This bilateral input from the spinal cord may contribute to the production of the large, bilateral receptive fields that characterize many of the neurons in Sm of rats (Dostrovsky and Guilbaud, 1988; Miletic and Coffield, 1989).

Recent anatomical studies led Apkarian and Hodge (1989a, b) to suggest that the input to Sm from the spinal cord may also be small in monkeys. Following injections of WGA-HRP into the lumbar cord, the authors found a small amount of what they interpreted to be terminal labeling within $\mathrm{Sm}$. In contrast, labeled axons in the central lateral and dorsal medial nuclei were found to be considerably more numerous and covered a much larger area. Also, Mantyh (1983a) reported that the spinal cord projection to Sm in monkeys was "light to moderate." However, others have reported denser terminal labeling in Sm of monkeys following injections of HRP into the spinal cord (Craig and Burton, 1981; Burton and Craig, 1983). Apkarian and Hodge (1989a) also have reported that large injections of WGA-HRP into the thalamus, that included $\mathrm{Sm}$, resulted in fewer labeled neurons in the marginal zone of the spinal cord than did injections which excluded $\mathrm{Sm}$. It would be valuable to examine directly the spinal projections to $\mathrm{Sm}$ in monkeys using restricted injections of retrograde tracers. 
Table 1. Mean ( \pm SD) numbers of neurons retrogradely labeled in alternate sections in nucleus caudalis and the spinal cord following iontophoretic injections of FG into nucleus submedius of 6 rats

\begin{tabular}{llclll} 
& NC & C1-2 & C4-5 & C7-8 & T4 \\
\hline SDH & $63.2 \pm 65.9$ & $0.3 \pm 0.5$ & $0.0 \pm 0.0$ & $0.0 \pm 0.0$ & $0.0 \pm 0.0$ \\
DDH & $15.0 \pm 14.9$ & $30.7 \pm 28.9$ & $3.0 \pm 5.5$ & $1.3 \pm 2.4$ & $1.2 \pm 1.9$ \\
IZ/VH & & $17.3 \pm 13.2$ & $2.8 \pm 4.7$ & $2.2 \pm 3.1$ & $1.0 \pm 1.3$ \\
ACC & & $2.2 \pm 1.2$ & $2.3 \pm 2.3$ & 0.6 & $0.7 \pm 1.0$ \\
LSN/LCN & & $1.7 \pm 1.9$ & $0.7 \pm 1.0$ & $1.3 \pm 1.5$ & $0.2 \pm 0.4$ \\
Total & $78.2 \pm 76.6$ & $52.2 \pm 43.2$ & $8.8 \pm 12.7$ & $6.0 \pm 7.3$ & $2.8 \pm 2.6$ \\
\hline
\end{tabular}

For abbreviations, see the Appendix.

Table 2. Numbers of neurons retrogradely labeled in alternate sections in nucleus caudalis and 18 spinal cord segments following injections of FG into areas near nucleus submedius of 13 rats

\begin{tabular}{|c|c|c|c|c|c|c|c|c|}
\hline \multicolumn{2}{|l|}{ Case } & \multirow{2}{*}{$\frac{\mathrm{NC}}{7}$} & \multirow{2}{*}{$\frac{\text { SDH }}{7}$} & \multirow{2}{*}{$\frac{\mathrm{DDH}}{61}$} & \multirow{2}{*}{$\begin{array}{l}\mathrm{IZ/} \\
\mathrm{VH} \\
50\end{array}$} & \multirow{2}{*}{$\frac{A C C}{23}$} & \multirow{2}{*}{$\begin{array}{l}\mathrm{LSN} / \\
\mathrm{LCN} \\
11\end{array}$} & \multirow{2}{*}{ 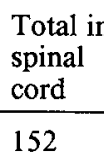 } \\
\hline NonSm & 1 & & & & & & & \\
\hline & 2 & 12 & 4 & 37 & 46 & 18 & 13 & 118 \\
\hline & 3 & 16 & 1 & 25 & 19 & 6 & 10 & 61 \\
\hline & 4 & 14 & 17 & 40 & 30 & 18 & 31 & 136 \\
\hline & 5 & 10 & 4 & 12 & 10 & 10 & 12 & 48 \\
\hline & 6 & 4 & 2 & 13 & 16 & 3 & 2 & 36 \\
\hline & 7 & 94 & 1 & 86 & 65 & 20 & 27 & 199 \\
\hline & 8 & 0 & 0 & 28 & 9 & 0 & 0 & 37 \\
\hline & 9 & 54 & 2 & 16 & 18 & 10 & 4 & 50 \\
\hline & 10 & 37 & 0 & 16 & 10 & 8 & 1 & 35 \\
\hline & 11 & 6 & 1 & 68 & 16 & 8 & 63 & 156 \\
\hline & 12 & 11 & 0 & 27 & 38 & 20 & 5 & 90 \\
\hline & 13 & 24 & 0 & 16 & 11 & 10 & 1 & 38 \\
\hline
\end{tabular}

\section{Functional considerations}

Only a single electrophysiological report has appeared in which spinal or medullary inputs to $\mathrm{Sm}$ have been carefully identified and characterized. Dostrovsky et al. (1987) examined the response properties of neurons in the superficial area of nucleus caudalis that project to $\mathrm{Sm}$ in cats. This study is of particular interest since the majority of input to $\mathrm{Sm}$ in rats (present study) and cats (Craig and Burton, 1981) originates in the spinal trigeminal nuclei. Approximately $14 \%$ of the neurons recorded were classified as nociceptive-specific. In contrast, $81 \%$ of the recorded neurons responded only to innocuous cooling of their receptive fields (Dostrovsky et al., 1987). These findings suggest that the large, direct afferent projection from nucleus caudalis to Sm primarily carries information regarding innocuous changes in the temperature of the skin.

Recently, we determined the total number of spinothalamic tract neurons in rats (Burstein et al., 1990b). Injections of FG were made that virtually filled the thalamus unilaterally. Following a 4-5 d survival period, the same 18 spinal cord segments

For abbreviations, see the Appendix.

Table 3. Numbers of neurons retrogradely labeled in alternate sections in nucleus caudalis and the spinal cord following pressure injections of Fast blue into nucleus submedius of 3 rats

\begin{tabular}{|c|c|c|c|c|c|c|c|c|c|c|c|c|}
\hline & $\mathrm{NC}$ & $\mathrm{C} 1-2$ & $\mathrm{C} 4-5$ & C7-8 & $\mathrm{T} 4$ & T6 & $\mathrm{T} 8$ & $\mathrm{~T} 12$ & L1-3 & L4-5 & L6-S2 & $\begin{array}{l}\text { Total in } \\
\text { spinal } \\
\text { cord }\end{array}$ \\
\hline \multicolumn{13}{|l|}{$\mathrm{Sm} 7$} \\
\hline $\mathrm{SDH}$ & 69 & 1 & 0 & 0 & 0 & 0 & 0 & 0 & 0 & 0 & 0 & 1 \\
\hline $\mathrm{DDH}$ & 6 & 8 & 2 & 3 & 0 & 1 & 0 & 2 & 0 & 0 & 1 & 17 \\
\hline IZ/VH & & 17 & 7 & 1 & 1 & 0 & 0 & 0 & 1 & 0 & 0 & 27 \\
\hline $\mathrm{ACC}$ & & 3 & 3 & 5 & 0 & 0 & 0 & 0 & 1 & 1 & 1 & 14 \\
\hline LSN/LCN & & 3 & 1 & 0 & 0 & 0 & 0 & 3 & 3 & 0 & 0 & 10 \\
\hline Total & 75 & 32 & 13 & 9 & 1 & 1 & 0 & 5 & 5 & 1 & 2 & 69 \\
\hline \multicolumn{13}{|l|}{ Sm8 } \\
\hline $\mathrm{SDH}$ & 89 & 0 & 0 & 0 & 0 & 0 & 0 & 0 & 0 & 1 & 2 & 3 \\
\hline $\mathrm{DDH}$ & 21 & 94 & 11 & 17 & 5 & 4 & 7 & 8 & 28 & 9 & 22 & 205 \\
\hline $\mathrm{IZ} / \mathrm{VH}$ & & 63 & 32 & 5 & 3 & 1 & 0 & 1 & 17 & 3 & 0 & 125 \\
\hline $\mathrm{ACC}$ & & 3 & 14 & 7 & 3 & 1 & 1 & 1 & 10 & 6 & 3 & 49 \\
\hline LSN/LCN & & 5 & 7 & 6 & 1 & 5 & 1 & 1 & 18 & 8 & 7 & 59 \\
\hline Total & 110 & 165 & 64 & 35 & 12 & 11 & 9 & 11 & 73 & 27 & 34 & 441 \\
\hline \multicolumn{13}{|l|}{ Sm9 } \\
\hline SDH & 56 & 1 & 0 & 3 & 1 & 0 & 0 & 0 & 0 & 2 & 1 & 8 \\
\hline $\mathrm{DDH}$ & 4 & 36 & 15 & 8 & 5 & 2 & 3 & 9 & 12 & 17 & 12 & 119 \\
\hline IZ/VH & & 44 & 25 & 3 & 2 & 2 & 1 & 2 & 7 & 2 & 2 & 90 \\
\hline $\mathrm{ACC}$ & & 4 & 18 & 6 & 0 & 1 & 1 & 4 & 5 & 5 & 1 & 45 \\
\hline LSN/LCN & & 6 & 9 & 2 & 2 & 0 & 0 & 0 & 6 & 5 & 3 & 33 \\
\hline Total & 60 & 91 & 67 & 22 & 10 & 5 & 5 & 15 & 30 & 31 & 19 & 295 \\
\hline
\end{tabular}

For abbreviations, see the Appendix. 


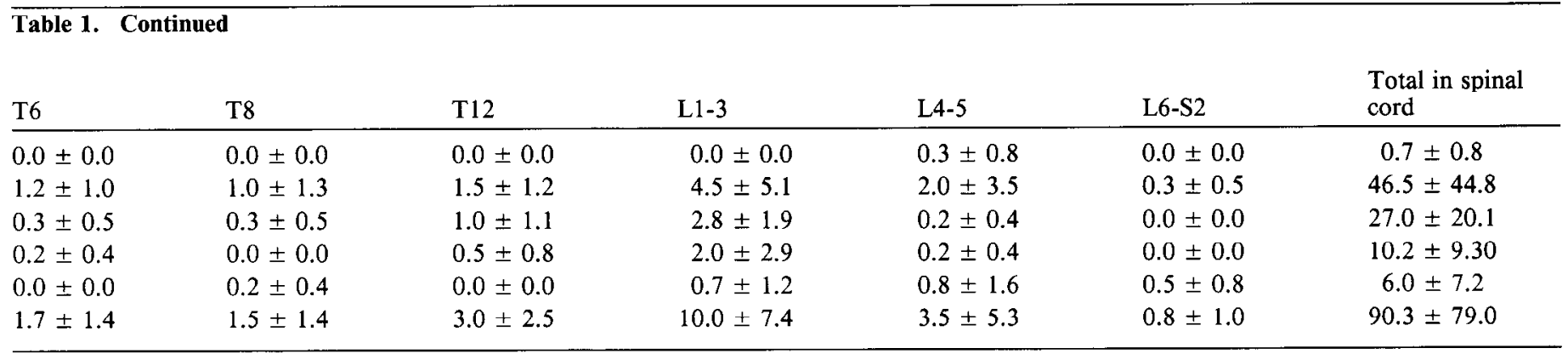

examined in the present study were removed, and labeled neurons were counted in alternate sections. An average of more than 4000 neurons was counted in the successful cases. In the present study using the same tracer and identical counting techniques, injections into nucleus submedius labeled an average of fewer than 100 neurons. A mean of approximately 420 neurons was counted in the superficial dorsal horn following injections that filled the thalamus (Burstein et al., 1990b). In contrast, the mean number of superficial dorsal horn neurons labeled following injections of FG that were restricted to Sm was less than 1. Therefore, it appears that in the rat, fewer than $5 \%$ of all spinothalamic tract neurons project to Sm. Similarly, fewer than $1 \%$ of spinothalamic tract neurons in the marginal zone project to $\mathrm{Sm}$.

Finally, it should be noted that although each of our total of more than 25 injections of retrograde tracers into the thalamus labeled neurons in the spinal cord, only those at the border of the posterior VBC and Po labeled large numbers of neurons in the marginal zone. As suggested previously by Menetrey et al. (1984), it might be useful to explore the input from the spinal cord to this area in more detail.

\begin{tabular}{ll}
\multicolumn{2}{l}{ Appendix } \\
Abbreviations \\
ACC & area around the central canal \\
AM & anterior medial nucleus \\
APN & anterior pretectal nucleus \\
AR & acoustic radiation \\
C & cervical spinal cord \\
CC & corpus callosum \\
CL & central lateral nucleus \\
CM & central medial nucleus \\
CN & cuneate nucleus \\
DC & dorsal columns \\
DDH & deep dorsal horn \\
DH & dorsal horn \\
DLF & dorsal lateral funiculus \\
DLG & dorsal lateral geniculate nucleus \\
F & fornix \\
Fi & fimbria hippocampus \\
FR & fasciculus retroflexus \\
GN & gracile nucleus \\
H & habenula \\
IC & internal capsule \\
ICP & inferior cerebellar peduncle \\
IZ & intermediate zone \\
L & lumbar spinal cord \\
LCN & lateral cervical nucleus \\
LD & lateral dorsal nucleus \\
LF & lateral funiculus \\
LP & lateral posterior nucleus \\
LRN & lateral reticular nucleus \\
LSN & lateral spinal nucleus \\
LV & lateral ventricle \\
& \\
\end{tabular}

\author{
medial dorsal nucleus \\ medial geniculate nucleus \\ medial lemniscus \\ mammillothalamic tract \\ nucleus caudalis \\ nucleus interpolaris \\ nucleus reticularis thalami \\ optic chiasm \\ optic tract \\ posterior commissure \\ posterior thalamic group \\ posterior thalamic group, triangular \\ prerubral field \\ paratenial thalamic nucleus \\ paraventricular thalamic nucleus \\ paraventricular thalamic nucleus, anterior \\ paraventricular hypothalamic nucleus \\ pyramidal decussation \\ nucleus reuniens \\ rhomboid nucleus \\ superficial dorsal horn \\ stria medullaris \\ nucleus submedius \\ supraoptic nucleus \\ nucleus of the solitary tract \\ supraoptic decussation \\ subparafascicular nucleus \\ stria terminalis \\ subthalamic nucleus \\ superior thalamic radiation \\ spinothalamic tract \\ spinal trigeminal tract \\ thoracic spinal cord \\ triangular septal nucleus \\ ventrobasal complex \\ ventral horn \\ ventral hippocampal commissure \\ ventrolateral geniculate nucleus \\ zona incerta \\ third ventricle \\ dorsal third ventricle \\ hypoglossal nucleus
}

\section{References}

Albe-Fessard D, Berkley KJ, Kruger L, Ralston HJ, Willis WD (1985) Diencephalic mechanisms of pain sensation. Brain Res Rev 9:217296.

Apkarian AV, Hodge CJ (1989a) Primate spinothalamic pathways: I. A quantitative study of the cells of origin of the spinothalamic pathway. J Comp Neurol 288:447-473.

Apkarian AV, Hodge CJ (1989b) Primate spinothalamic pathways: III. Thalamic terminations of the dorsolateral and ventral spinothalamic pathways. J Comp Neurol 288:493-511.

Bullitt E (1989) Induction of c-fos-like protein within the lumbar spinal cord and thalamus of the rat following peripheral stimulation. Brain Res 493:391-397.

Burstein R, Cliffer KD, Giesler GJ Jr (1987) Direct somatosensory projections from the spinal cord to the hypothalamus and telencephalon. J Neurosci 7:4159-4164. 
Burstein R, Cliffer KD, Giesler GJ Jr (1990a) The cells of origin of the spinohypothalamic tract in the rat. J Comp Neurol 291:329-344.

Burstein R, Dado RJ, Giesler GJ Jr (1990b) The cells of origin of the spinothalamic tract of the rat: a quantitative reexamination. Brain Res 511:329-337.

Burton H, Craig AD (1983) Spinothalamic projections in cat, raccoon and monkey: a study based on anterograde transport of horseradish peroxidase. In: Somatosensory integration in the thalamus (Macchi G, Rustioni A, Spreafico R, eds), pp 17-41. Amsterdam: Elsevier.

Carstens E, Trevino DL (1978) Anatomical and physiological properties of ipsilaterally projecting spinothalamic neurons in the second cervical segment of the cat's spinal cord. J Comp Neurol 182:167184.

Christensen BN, Perl ER (1970) Spinal neurons specifically excited by noxious or thermal stimuli: marginal zone of the dorsal horn. J Neurophysiol 33:293-307.

Coffield JA, Miletic V (1987) Immunoreactive enkephalin is contained within some trigeminal and spinal neurons projecting to the rat medial thalamus. Brain Res 425:380-383.

Craig AD Jr, Burton H (1981) Spinal and medullary lamina I projection to nucleus submedius in medial thalamus: a possible pain center. J Neurophysiol 45:443-466.

Craig AD Jr, Burton H (1985) The distribution and topographical organization in the thalamus of anterogradely-transported horseradish peroxidase after spinal injections in cat and raccoon. Exp Brain Res 58:227-254.

Craig AD Jr, Wicgand SJ, Price JL (1982) The thalamo-cortical projection of the nucleus submedius in the cat. J Comp Neurol 206:2848.

Craig AD Jr, Linington AJ, Kniffki K-D (1989a) Significant differences in the retrograde labeling of spinothalamic tract cells by horseradish peroxidase and the fluorescent tracers fast blue and diamidino yellow. Exp Brain Res 74:431-436.

Craig AD Jr, Linington AJ, Kniffki K-D (1989b) Cells of origin of spinothalamic tract projections to the medial and lateral thalamus in the cat. J Comp Neurol 289:568-585.

Dostrovsky JO, Guilbaud G (1988) Noxious stimuli excite neurons in nucleus submedius of the normal and arthritic rat. Brain Res 460: 269-280.

Dostrovsky JO, Guilbaud G (1990) Nociceptive responses in medial thalamus of the normal and arthritic rat. Pain 40:93-104.

Dostrovsky JO, Broton JG, Warma NK (1987) Functional properties of subnucleus caudalis lamina I neurons projecting to nucleus submedius. In: Fine afferent nerve fibers and pain (Schmidt RF, Schaible H-G, Vahle-Hinz C, eds), pp 359-366. Weinheim: VCH.

Dostrovsky JO, Yoshida A, Chiang CY, Sessle BJ (1989) Brainstem afferents and cortical projections of the rat nucleus submedius. Soc Neurosci Abstr 15:1188.

Giesler GJ Jr, Menetrey D, Basbaum AI (1979) Differential origins of spinothalamic tract projections to medial and lateral thalamus in the rat. J Comp Neurol 184:107-126.

Giesler GJ Jr, Spiel HR, Willis WD (1981) Organization of spinothalamic tract axons within the rat spinal cord. J Comp Neurol 195:243252.

Herkenham M (1979) The afferent and efferent connections of the ventromedial thalamic nucleus in the rat. J Comp Neurol 183:487518

Hunt SP, Pini A, Evan G (1987) Induction of c-fos-like protein in spinal cord neurons following sensory stimulation. Nature 328:632634.

Jones EG, Leavitt RY (1974) Retrograde axonal transport and the demonstration of non-specific projections to the cerebral cortex and striatum from thalamic intralaminar nuclei in the rat, cat and monkey. J Comp Neurol 154:349-378.
Kevetter GA, Willis WD (1983) Collaterals of spinothalamic cells in the rat. J Comp Neurol 215:453-464.

Krettek JE, Price JL (1977) The cortical projections of the mediodorsal nucleus and adjacent thalamic nuclei in the rat. J Comp Neurol 171: 157-192.

Kumazawa T, Perl ER, Burgess PR, Whitehorn D (1975) Ascending projections from marginal zone (lamina I) neurons of the spinal dorsal horn. J Comp Neurol 162:1-12.

Lund RD, Webster KE (1967) Thalamic afferents from the spinal cord and trigeminal nuclei: an experimental anatomical study in the rat. J Comp Neurol 130:313-328.

Ma W, Peschanski M, Besson JM (1986) The overlap of spinothalamic and dorsal column nuclei projections in the ventrobasal complex of the rat thalamus: a double anterograde labeling study using light microscopy analysis. J Comp Neurol 245:531-540.

Ma W, Peschanski M, Ohara PT (1988) Fine structure of the dorsal part of the nucleus submedius of the rat thalamus: an anatomical study with reference to possible pain pathways. Neuroscience 26:147159.

Mantyh PW (1983a) The spinothalamic tract in the primate: a reexamination using wheatgerm agglutinin conjugated to horseradish peroxidase. Neuroscience 9:847-862.

Mantyh PW (1983b) The terminations of the spinothalamic tract in the cat. Neurosci Lett 38:119-124.

Mehler WR (1969) Some neurological species differences-a posteriori. Ann NY Acad Sci 167:424-468.

Menetrey D, De Pommery J, Roudier F (1984) Properties of deep spinothalamic tract cells in the rat, with special reference to ventromedial zone of lumbar dorsal horn. J Neurophysiol 52:612-624.

Miletic V, Coffield JA (1989) Responses of neurons in the rat nucleus submedius to noxious and innocuous mechanical cutaneous stimulation. Somatosens Motor Res 6:567-587.

Nahin RL (1988) Immunocytochemical identification of long ascending, peptidergic lumbar spinal neurons terminating in either the medial or lateral thalamus in the rat. Brain Res 443:345-349.

Paxinos G, Watson C (1986) The rat brain in stereotaxic coordinates. Sydney: Academic.

Peschanski M (1984) Trigeminal afferents to the diencephalon in the rat. Neuroscience 12:465-487.

Peschanski M, Mantyh PW, Besson JM (1983) Spinal afferents to the ventrobasal thalamic complex in the rat: an anatomical study using wheat-germ agglutinin conjugated to horseradish peroxidase. Brain Res 278:240-244.

Pieribone VA, Aston-Jones G (1988) The iontophoretic application of Fluoro-Gold for the study of afferents to deep brain nuclei. Brain Res 475:259-271.

Price DD, Dubner R, Hu JW (1976) Trigeminothalamic neurons in nucleus caudalis responsive to tactile, thermal, and nociceptive stimulation of monkey's face. J Neurophysiol 39:936-953.

Robertson B, Grant G, Bjorkeland M (1983) Demonstration of spinocerebellar projections in cat using anterograde transport of WGAHRP, with some observations on spinomesencephalic and spinothalamic projections. Exp Brain Res 52:99-104.

Schmued LC, Fallon JH (1986) Fluoro-Gold: a new fluorescent retrograde axonal tracer with numerous unique properties. Brain Res 377 147-154.

Torvik A (1956) Afferent connections to the sensory trigeminal nuclei, the nucleus of the solitary tract and adjacent structures: an experimental study in the rat. J Comp Neurol 106:51-132.

Zemlan FP, Leonard CM, Kow LM, Pfaff DW (1978) Ascending tracts of the lateral spinal columns of the rat spinal cord: a study using silver impregnation and horseradish peroxidase techniques. Exp Neurol 62: 298-334. 